\title{
Residual Stress Measurement of Fiber Metal Laminates Using Incremental Hole-Drilling Technique in Consideration of the Integral Method
}

\author{
A.R. Ghasemi*, M.M. Mohammadi \\ Department of Mechanical Engineering, University of Kashan, Kashan, Iran \\ * P.O.B. 8731753153, ghasemi@kashanu.ac.ir
}

\begin{abstract}
In this manuscript, integral method was used for the approximation of residual stresses field in fiber-metal laminates (FMLs). Initially, calibration coefficients matrix for the integral method were determined numerically by the finite element program using ANSYS software. The calibration coefficients were used to relate the measured strains relaxation field with the existing residual stresses prior to the IHD process. Subsequently, FML specimens with symmetric stacking sequence of $\left[\mathrm{AL} / 0_{2}^{\circ} / 90_{2}^{\circ}\right]_{\mathrm{S}}$ were manufactured. Next, the IHD experiment by high speed drilling machine were performed and released strains caused by the change in hole-geometry have been obtained. Finally, experimental results from IHD experiment were compared with the theoretical predictions from classical lamination theory. Very good agreements with the experimental and theoretical results show that, the IHD technique can be successfully applied for measuring residual stresses in FML composites.
\end{abstract}

Keywords: Fiber Metal Laminates, Incremental Hole-Drilling Technique, Integral Method, Calibration Coefficients Matrix, Classical Lamination Theory. 


\section{Introduction}

Fiber metal laminates (FMLs) are a new type of hybrid composite structures which consists of thin sheet layers of metal alloys and plies of fiber reinforced polymer composites (Fig. 1) [1]. FMLs combine the superior durability of metals with the attractive properties of fiber-reinforced composite materials such as high fatigue resistance, good moisture resistance, excellent impact, corrosion resistance, fire resistance, weight-savings and specialized strength properties [2]. The most commercially available FMLs are ARALL (aramid reinforced aluminium laminate), CARALL (carbon reinforced aluminium laminate), and GLARE (glass reinforced aluminium laminate) [3].

There are many articles about experimental and theoretical investigations, regarding to adhesion between metal sheet and fiber, stacking arrangements, mechanical properties, composite volume fractions and etc. [4-6], while there are a limited number of studies concerning the residual stresses in FML materials. Therefore, this important issue still need more understanding and attention.

The residual stresses in FML materials are produced during the fabrication process. Shrinkage during curing and the mismatch of coefficients of thermal expansion (CTE) between metal sheet, fiber and matrix are the most important reasons for residual stresses [7]. The magnitudes of these stresses depend on material properties, lay-ups and curing cycle (non-uniform heating or cooling during manufacturing) [8]. Residual stresses reduce the performance of composite structures and can cause matrix cracking, fiber breakage, delamination, warpage, interface debonding and dimensional instability $[9,10]$.

There are a number of destructive and non-destructive methods, which are used for determination of residual stresses. One of them is hole drilling method [11]. This method is one of the most currently and widely used methods for residual stress measurement. It is standard, relatively simple, inexpensive, quick, versatile, and well adapted method to a wide range of materials [11-12]. This method is well established for measuring the residual stresses in homogeneous isotropic materials.

The basic hole drilling calculations described in ASTM E837 [11] is applicable to the residual stress profile determination where in-plane stress gradients are small. The stresses may remain approximately constant with depth (uniform stresses) or they may vary significantly with depth (non-uniform stresses). Only uniform stress 
measurements are specified for thin workpieces, while both uniform and non-uniform stress measurements are specified for thick workpieces. More recently, focus has fallen on measuring the variation of the residual stress with depth by the incremental hole drilling (IHD) method and developing solutions for non-uniform residual stresses fields. The most common way of estimating non-uniform residual stress distributions in the IHD method is integral method.

The hole drilling method for determination of non-uniform residual stresses in isotropic and orthotropic materials have been developed well. Shajer [13-14], Flaman et al. [1517], Sicot et al. [18-19], Pagliaro and Zuccarello [20], Ghasemi et al. [21-22], and Shokrieh and Ghasemi [23-24] have studied the determination of non-uniform residual stresses in metal and composite materials based on the IHD method. Extending the hole drilling method to determine the residual stresses in orthotropic materials was presented by Schajer and Yang [25]. The released strains, which are measured by the hole drilling method, are converted to the residual stresses using calibration coefficients. These coefficients can be determined by closed form, numerical, and experimental methods. Shokrieh and Ghasemi [23] simulated the hole drilling method for measurement the residual stresses in isotropic, orthotropic, and laminated composites. They also presented an exact solution for prediction of calibration coefficients in points of strain gauge rosette for the orthotropic materials. Using these factors, the residual stresses can be obtained from the measured strains based on the CHD experiment [24].

Drilling speed and feed rate are important parameters in hole drilling method. Flaman and Herring [16] used the high-speed turbine and carbide milling blades for measuring the residual stresses. Andersen [26] used the normal milling method on thick isotropic samples, regardless of its effect on the measurement precision of the strains released. He indicated that the normal hole drilling method could be used to calculate the residual stresses in depth of the specimens with no effect on the accuracy of the measurements. The hole drilling of multi-layer composites at milling speed of $5000 \mathrm{r} / \mathrm{min}$ and feed rate of $10 \mathrm{~mm} / \mathrm{s}$ has been done by Sicot et al. [18-19]. Ghasemi and Shokrieh [27-28] used the hole drilling of multi-layer composites using a high-speed CNC milling machine during determination of non-uniform residual stresses. The results showed that incremental hole drilling can be properly used for determination of non-uniform residual stresses in composite and metal materials. 
The main purpose of this study is developing a theoretical, numerical and experimental study regarding the evolution of non-uniform residual stresses in FML materials from incremental strain data by the integral method. For this purpose initially, numerical models using finite element (FE) method are used to determine the calibration coefficients of the IHD method. For model verification, the FML specimens with $\left[\mathrm{AL} / 0_{2}^{\circ} / 90_{2}^{\circ}\right]_{\mathrm{S}}$ lay-ups are fabricated. Subsequently, by installing a strain gauge rosette on the surface of each specimen, and measuring the incremental strains, the residual stresses in each step of the IHD experiment are determined. Finally, to validate the accuracy of the experimental results, the residual stresses are also compared with the values predicted by theoretical methods. The theoretical study relies on the classical laminate theory (CLT).

\section{Principles of incremental hole drilling method}

In this section, the IHD method is presented to measure experimentally with accuracy residual stresses in each ply of a laminate. In this method, a strain gauge rosette is placed on $0^{\circ}, 90^{\circ}$ and $225^{\circ}$ in surface of specimen containing the residual stresses (Fig. 2). This method involves three major aspects to determine the non-uniform residual stresses distribution in depth:

- Drilling a small hole in the specimen in the area of interest,

- Measuring the released strains around the hole, using strain gauges rosette,

- Computing the corresponding residual stresses, using recorded strains.

The major error which may have appeared the IHD method and almost all other destructive methods for measuring residual stresses is due to the physical limitations [13-14]. The sensitivity of the IHD method reduces with the hole-depth. In this method, the rosette is attached on the samples surface and the strains on the parts surface are read, while the non-uniform stresses are through the thickness. This difference in the locations of the target stresses and the measured strains creates a substantial computational challenge [29]. Therefore, for the IHD method, the relationship between the residual stresses and the measured strains does not have a simple one to one form and has the form of an integral equation [30]: 
$\varepsilon\left(h_{i}\right)=\int_{0}^{h_{i}} C\left(x, h_{i}\right) \sigma(x) d x \quad 1 \leq i \leq n$

where $\varepsilon\left(h_{i}\right)$ is the measured strain in the hole-depth " $h_{i}$ ". $\sigma(x)$ is corresponded to the residual stresses and Kernel function $C\left(x, h_{i}\right)$ describes the measured strain caused by a unit stress at depth " $x$ " within a hole-depth " $h_{i}$ ". In the hole drilling method, this function is usually obtained using a FE analysis.

In order to solve Eq. 1, an initial distribution for the residual stresses must be considered. The most important methods to estimate residual stresses in the IHD method are the integral, incremental strain, power series and average stress methods [31]. Integral method considers a constant and uniform residual stress analysis at each hole-depth increment (Fig. 3). The assumptions are that each step of drilling is influenced by the previous one. Therefore this method is suitable for calculating of nonuniform residual stresses. The unknown residual stresses in the integral method are estimated by the Eq. (2) [30]:

$\sigma\left(x_{j}\right)=\sum_{j=1}^{n} \sigma_{j} U_{j}(x) h_{j-1} \leq x \leq h_{j}$

where, $\sigma_{j}$ is the value of residual stress at the $j^{\text {th }}$ hole-depth increment and " $n$ " is the total number of increments. The pulse functions $U_{j}(x)$ are defined as follows (Eq. 3):

$$
U_{j}(x)=\left\{\begin{array}{cc}
1 & h_{j-1} \leq x \leq h_{j} \\
0 & x<h_{j-1}, x>h_{j}
\end{array}\right.
$$

Substituting Eq. (2) in Eq. (1) results in:

$\varepsilon\left(h_{i}\right)=\sum_{j=1}^{n} \sigma_{j}\left(\int_{0}^{h_{i}} C\left(x, h_{i}\right) U_{j}(x) d x\right)=\sum_{j=1}^{n} C_{i j} \sigma_{j}$

Therefore the elements of calibration coefficient $C_{i j}$ are expressed by the Eq. (5):

$C_{i j}=\int_{0}^{h_{i}} C\left(x, h_{i}\right) U_{j}(x) d x=\int_{h_{j-1}}^{h_{j}} C\left(x, h_{i}\right) d x$

Comparison between Eq. (5) and Eq. (1) indicates that a specific element of matrix $C_{i j}$, represents the measured strain at the strain gauge location for a hole of depth $h_{i}$ when the residual stress distribution at the domain $h_{j-1} \leq x \leq h_{j}$ is equal to the unit load (Eq. 6):

$C_{i j}=\varepsilon\left(h=h_{i}, \sigma(x)=U_{j}(x)\right)$

The compact form of Eq. (4) is expressed as a matrix equation: 
$\left[C_{i j}\right]\left[\sigma_{\text {step }, j}\right]=\left[\varepsilon_{\text {step }, i}\right]$

where:

$C_{i j}=\left[\begin{array}{lll}C_{i j}^{11} & C_{i j}^{12} & C_{i j}^{13} \\ C_{i j}^{21} & C_{i j}^{22} & C_{i j}^{23} \\ C_{i j}^{31} & C_{i j}^{32} & C_{i j}^{33}\end{array}\right]$

$\sigma_{\text {step }, j}=\left[\begin{array}{c}\sigma_{\text {step }, j}^{x} \\ \sigma_{\text {step }, j}^{x y} \\ \sigma_{\text {step }, j}^{y}\end{array}\right]$

$\varepsilon_{\text {step }, i}=\left[\begin{array}{c}\varepsilon_{\mathrm{step}, i}^{1} \\ \varepsilon_{\mathrm{step}, i}^{2} \\ \varepsilon_{\mathrm{step}, i}^{3}\end{array}\right]$

where $\left\{\varepsilon^{1}, \varepsilon^{2}, \varepsilon^{3}\right\}^{T}$ is the vector containing the strain relaxation values measured by the strain gauges 1,2 and 3 , respectively (see Fig.2). $\left\{\sigma^{x}, \sigma^{x y}, \sigma^{y}\right\}^{T}$, contain the longitudinal, transverse, and in-plane shear residual stresses existing in a given ply $i$, relates to principal laminate system X-Y. Also, matrix element $C_{i j}$ includes calibration coefficients and represents the total surface deformation measured after hole-depth increment $i$ caused by a unit load within increment $j$.

Substituting, Eqs. (8) and (10) in Eq. (7), the general relationship between the measured strain data and the residual stresses within four depth increments is given by the Eq. (11). In this case, the matrix $C_{i j}$ is square and lower triangular. 


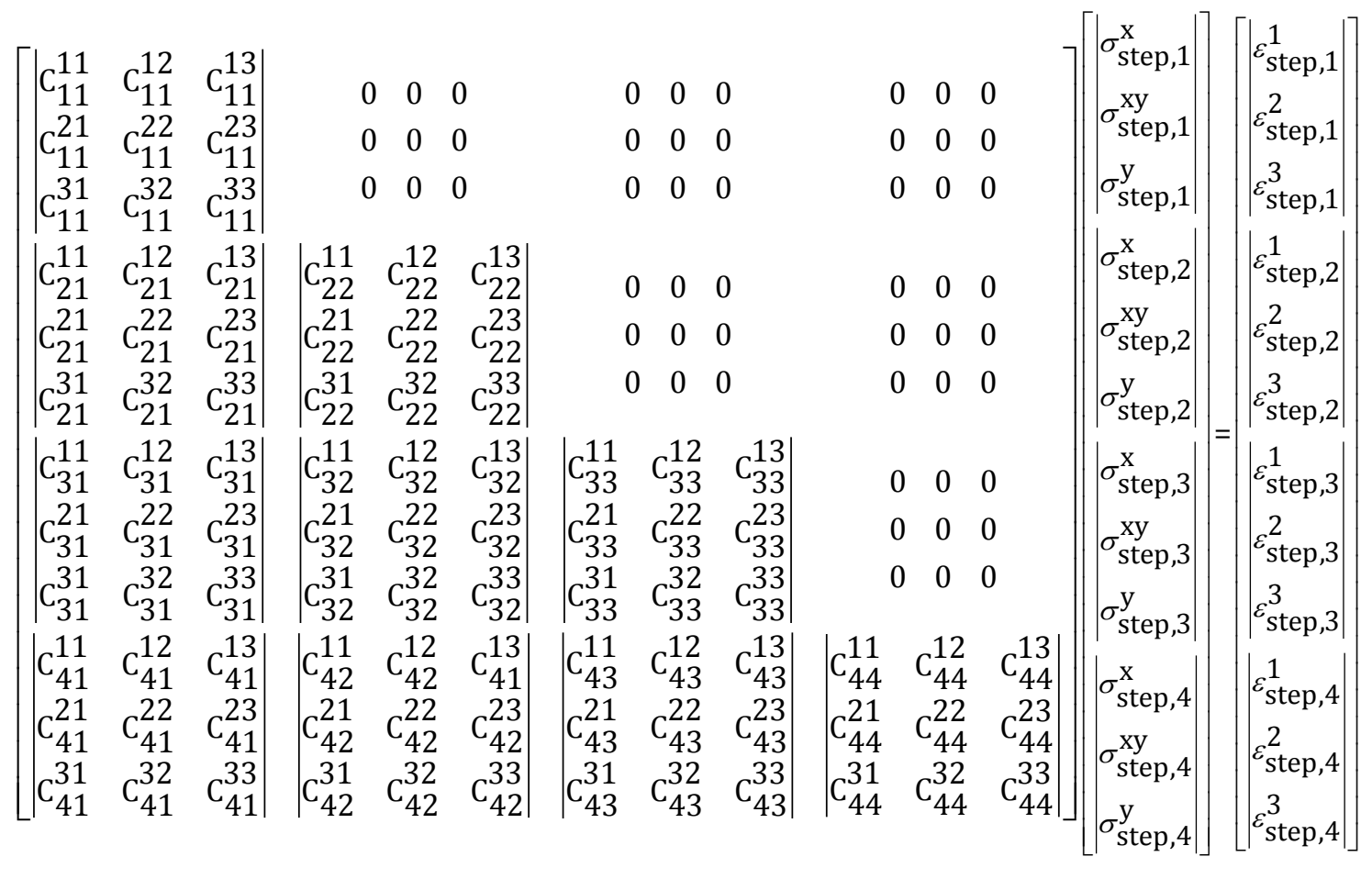

\section{Finite Element Modeling}

\subsection{Theory}

Relation between measured strains and residual stresses in the integral hole drilling method is shown in Fig. 4.

By this method, it is considered that for each increment in hole-depth, the total strain measured on the surface can be divided into two parts:

- The first one is due to the residual stresses on the removed layer.

- The second one is the contribution of the residual stresses redistribution caused by the change in hole-geometry.

Changing of the hole-geometry provides the possibility of more released strains to the specimen in comparison with the previous steps. Accordingly, different sets of matrix $C_{i j}$ are required to relate the measured strain to interior stresses for each of the stressdepth and hole-depth combinations shown in Fig. 5. $C_{i j}$ is the calibration coefficients matrix for the $i$ th increment and loading on the $j$ th layer.

During the integral hole-drilling method:

At the first, the material from at the first hole-depth increment is removed and then released strains that relate directly to the residual stresses relieved at the holeboundary within that increment are measured. 
At the second, the material from at the second hole-depth increment is removed and the released strains may be classified into two groups:

- The strains released due to hole-depth increase which are associated to the $\left[C_{21}\right]$ matrix.

- The strains resulted from the residual stresses within the second increment which are proportional to the $\left[C_{22}\right]$ matrix.

By increasing the hole-depth via third drilling increment, the strains released due to the depth increase are classified into two groups:

- The effect of residual stresses within the first increment on the strains at the third drilling increment, $\left[C_{31}\right]$ matrix.

- The effect of residual stresses within the second increment on the strains at the third drilling increment, $\left[C_{32}\right]$ matrix.

Also, the effect of residual stresses confined in the third increment is shown by $\left[C_{33}\right]$ matrix. The effect of the depth increase on calculation of the residual stresses in other increments may also be expressed in the same above mentioned manner.

According to the explanations provided in this section, the following step-by-step procedure was used to determine the magnitudes of the residual stresses in each increment of integral hole-drilling method:

- Residual stresses in the first drilling increment:

$\left[C_{11}\right]\left[\sigma_{\text {step }, 1}\right]=\left[\varepsilon_{\text {step }, 1}\right]$

$\left[\begin{array}{l}\sigma_{\text {step }, 1}^{x} \\ \sigma_{\text {step }, 1}^{x y} \\ \sigma_{\text {step }, 1}^{y}\end{array}\right]=\left[\begin{array}{lll}C_{11}^{11} & C_{11}^{12} & C_{11}^{13} \\ C_{11}^{21} & C_{11}^{22} & C_{11}^{23} \\ C_{11}^{31} & C_{11}^{32} & C_{11}^{33}\end{array}\right]^{-1}\left[\begin{array}{c}\varepsilon_{\text {step }, 1}^{1} \\ \varepsilon_{\text {step }, 1}^{2} \\ \varepsilon_{\text {step }, 1}^{3}\end{array}\right]$

- Residual stresses in the second drilling increment:

$\left[C_{21}\right]\left[\sigma_{\text {step }, 1}\right]+\left[C_{22}\right]\left[\sigma_{\text {step }, 2}\right]=\left[\varepsilon_{\text {step }, 2}\right]$

$\left[\begin{array}{l}\sigma_{\text {step }, 2}^{x} \\ \sigma_{\text {step }, 2}^{x y} \\ \sigma_{\text {step }, 2}^{y}\end{array}\right]=\left[\begin{array}{lll}C_{22}^{11} & C_{22}^{12} & C_{22}^{13} \\ C_{22}^{21} & C_{22}^{22} & C_{22}^{23} \\ C_{22}^{31} & C_{22}^{32} & C_{22}^{33}\end{array}\right]^{-1}\left(\left[\begin{array}{c}\varepsilon_{\text {step }, 2}^{1} \\ \varepsilon_{\text {step }, 2}^{2} \\ \varepsilon_{\text {step }, 2}^{3}\end{array}\right]-\left[\begin{array}{lll}C_{21}^{11} & C_{21}^{12} & C_{21}^{13} \\ C_{21}^{21} & C_{21}^{22} & C_{21}^{23} \\ C_{21}^{31} & C_{21}^{32} & C_{21}^{33}\end{array}\right]\left[\begin{array}{c}\sigma_{\text {step }, 1}^{x} \\ \sigma_{\text {step }, 1}^{x y} \\ \sigma_{\text {step }, 1}^{y}\end{array}\right]\right)$

\subsection{Simulation}

As previously mentioned, in the IHD method, the residual stresses are calculated from measured strains according to some mathematical functions, which represent the 
calibration coefficients matrix. These coefficients depend on the hole-geometry, used strain gauge rosette, and the relative position of layers [21, 23, 29]. It is possible to obtain them from the FE simulation. The concept of the determination of the calibration coefficients by the FE simulation is based on the principle of superposition. According to this principle, when a hole is introduced to a specimen with the residual stresses, the released strains due to the hole-drilling could be determined by applying loads opposed to the faces of the hole of a specimen without residual stresses in the FE model.

In order to calculate the calibration coefficient values, a subroutine has been developed in ANSYS parametric design language (APDL) to simulate the integral hole drilling method. The model used three-dimensional 20-node layered solid elements (Solid185) to simulate the orientation of the plies in each drilled hole-depth increment. All geometrical parameters, applied loads and elastic properties of each material ply are taken into account. Also, the structural surface effect element (Surf154) has been used to apply load to the hole-walls in the FE model. In Figs. 6 and 7, the three-dimensional FE model and the location of the strain gauge rosette and the hole-geometry, used for the simulation of integral hole-drilling method are shown.

Each layer of the FML composites is modeled separately. So, each layer has its own thermo-mechanical properties, fiber orientation and thickness. Then, all parts of the model are merged together. This model is based on the geometry and the strain gauge rosette arrangement of the specimens of the experimental calibration. The geometrical parameters of this model are illustrated on Table 1, and thermo-mechanical properties of the FML composite reported in Table 2.

To compute numerically the nine calibration coefficients $\left[C_{i j}\right]$, three load cases should be considered, consist of loading in $\mathrm{x}$-axis $\left(\sigma_{x}=1\right)$, loading in y-axis $\left(\sigma_{y}=1\right)$ and shear loading in xy-plane $\left(\sigma_{x y}=1\right)$. In order to apply each of these loads, the uniform load is applied simultaneously to the hole-edge. After applying the initial loads as the residual stress, to simulate the each step of the IHD process, the elements in the hole-area are removed and then strains in individual strain gauges are determined. This procedure is repeated until all calibration coefficients matrix are determined.

For the calculation of the $C_{i j}^{11}, C_{i j}^{21}$ and $C_{i j}^{31}$ coefficients (the first column of the Eq. 8) based on stress transformation equations, a radial stress equal to $\sigma_{r r}=\cos ^{2} \theta$ should be applied simultaneously at the hole boundaries of each depth-increment. Moreover, 
for the calculation of the $C_{i j}^{31}, C_{i j}^{32}$ and $C_{i j}^{33}$ coefficients (the third column of the Eq. 8), a radial stress equal to $\sigma_{r r}=\sin ^{2} \theta$ should be applied at the hole boundaries of each depth-increment in the FE model. Finally, the $C_{i j}^{12}, C_{i j}^{22}$ and $C_{i j}^{32}$ coefficients (the second column of the Eq. 8) can be computed by applying to the inside surface of the hole, a shear stress filed equal to $\sigma_{r r}=\sin 2 \theta$, as shown in Fig. 8. In the other words, $C_{i j}^{31}, C_{i j}^{32}$ and $C_{i j}^{33}$ coefficients are the effects of the shear stress on the measured strains along the gauge\#1 $\left(\theta=0^{\circ}\right)$, gauge\#2 $\left(\theta=45^{\circ}\right)$ and gauge\#3 $\left(\theta=90^{\circ}\right)$. In the following section, these three groups of calibration coefficient matrix are calculated by the FE analysis.

\subsection{Determinations of the calibration coefficients matrix}

The calibration coefficients in the relationship between the residual stresses and relieved strains are critical and need to be determined. In previous section, the integral hole drilling method has been simulated incrementally, at the center of the FE model using the element removal technique. In this section, the symmetric cross ply GLARE laminate with $\left[\mathrm{AL} / 0_{2}^{\circ} / 90_{2}^{\circ}\right]_{\mathrm{S}}$ lay-up is used to calculate calibration coefficients. The thickness of each hole-depth increment is considered to be $0.4 \mathrm{~mm}$ and equal to the imposed during the experimental tests. Hence, the first step is drilling the aluminium layer, the second step is drilling two composite layers with fiber orientation $0^{\circ}$, and the third step is drilling two composite layers with fiber orientation $90^{\circ}$. The results from calibration coefficients matrix for three steps of drilling are given in Eq. 16.

\begin{tabular}{|c|c|c|c|c|c|c|c|c|}
\hline-4.8902 & 0 & 1.9150 & & $\begin{array}{lll}0 & 0 & 0\end{array}$ & & & $\begin{array}{lll}0 & 0 & 0\end{array}$ & \\
\hline-1.4855 & -6.7276 & -1.4631 & & $\begin{array}{lll}0 & 0 & 0\end{array}$ & & & $\begin{array}{lll}0 & 0 & 0\end{array}$ & \\
\hline 1.8419 & 0 & -4.9250 & & $\begin{array}{lll}0 & 0 & 0\end{array}$ & & & $\begin{array}{lll}0 & 0 & 0\end{array}$ & \\
\hline-5.0561 & 0 & 2.0474 & -5.2645 & 0 & 2.4983 & & $\begin{array}{lll}0 & 0 & 0\end{array}$ & \\
\hline-1.4736 & -6.8946 & -1.4626 & -1.4339 & -7.5129 & -1.3328 & & $\begin{array}{lll}0 & 0 & 0\end{array}$ & \\
\hline 2.0294 & 0 & -5.0558 & 2.3720 & 0 & -5.2463 & & $\begin{array}{lll}0 & 0 & 0\end{array}$ & \\
\hline-5.0564 & 0 & 2.0470 & -5.2566 & 0 & 2.4844 & -5.1801 & 0 & 2.4199 \\
\hline-1.4738 & -6.8947 & -1.4629 & -1.4341 & -7.4988 & -1.3373 & -1.4047 & -7.4164 & -1.3612 \\
\hline 2.0292 & 0 & -5.0561 & 2.3622 & 0 & -5.2384 & 2.3494 & 0 & -5.2241 \\
\hline
\end{tabular}

According to the Eq.16, the following results are made:

1- In all calibration coefficients matrix of symmetric cross ply GLARE laminate, $C_{i j}^{12}$ and $C_{i j}^{32}$ factors are equal to zero. These coefficients are the effects of the shear residual stresses on the measured strains along the strain gauges in the $0^{\circ}$ and $90^{\circ}$ direction. 
Therefore, because of the absence of shear residual stresses in cross-ply laminate, these coefficients are equal to zero.

2- By increasing the hole-depth increment, the difference between numerical values of the calibration coefficients matrix has been reduced. This reduction means that the effects of the upper layers with farther distance on drilling of the lower layers has been reduced. In other word, with an increase in the hole-depth, the effects of released strains in depth reduced on the surface. This important result simplifies the usage of integral method in FML materials.

\section{Experimental Procedure}

\subsection{Materials and fabrication process}

The FML specimens used in this study have been fabricated using 3105-H14 aluminium alloy, ML-506 epoxy resin with a combined UT-E250 unidirectional glass fibers. The ML506 epoxy resin based on bisphenol-F has been mixed with a polyamine hardener HA11 at 100:15 ratio for fabrication of specimens. The FML specimens with dimensions of 150x150 $\mathrm{mm}^{2}$ have been manufactured using hand lay-up method with the symmetric stacking sequence of $\left[\mathrm{AL} / 0_{2}^{\circ} / 90_{2}^{\circ}\right]_{S}$. The thickness of composite layers is $0.2 \mathrm{~mm}$ with fiber volume fraction of 55\%. In the curing procedure, the specimens is left for 24 hours at $25^{\circ} \mathrm{C}$, then it is heated using an oven at $60^{\circ} \mathrm{C}$ for 6 hours with heating rate $5{ }^{\circ} \mathrm{C} / \mathrm{min}$ and finally is left to cool down at $25^{\circ} \mathrm{C}$ at ambient conditions. Information regarding the thermo-mechanical properties of FML specimens is mentioned in Table 2. The tensile tests are performed according to the ASTM standards to obtain the in-plane elastic properties of the composite layers. Also, to determine the thermal properties of individual lamina, Schapery's formula [32] is used.

$\alpha_{L}=\frac{E_{f} \alpha_{f} V_{f}+E_{m} \alpha_{m} V_{m}}{E_{f} V_{f}+E_{m} V_{m}}$

$\alpha_{T}=\alpha_{f} V_{f}+\alpha_{m} V_{m}+\left(\alpha_{f}-\alpha_{m}\right) \frac{v_{f} E_{m}-v_{m} E_{f}}{\frac{E_{f}}{V_{m}}+\frac{E_{m}}{V_{f}}}$

where, $\mathrm{E}$ is modulus of elasticity, $\alpha$ is thermal expansion coefficient, $\mathrm{V}$ is volume fraction, and $v$ is Poisson's ratio. Also, $m, f, L$ and $T$ indicate the matrix, fiber, longitudinal direction and transverse direction of the materials, respectively. 


\subsection{Drilling operations and drill bit}

The strain gauge rosette used in this research is FRS-2 supplied from TML company, which is especially suited to measure the residual stresses. This rosette has $1.3 \times 1.5 \mathrm{~mm}$ dimensions and a gauge circle diameter of $5.14 \mathrm{~mm}$. The IHD process is carried out using a high speed drilling machine as shown in Fig. 9. The translation speed (feeding speed) is fixed at $20 \mu \mathrm{m} / \mathrm{s}$ and the rotational speed (spindle speed) at $5000 \mathrm{rpm}$. Also, the diameter of the drill bit is $2 \mathrm{~mm}$. The IHD experiment of FML specimens by the high speed drilling machine provides a high accuracy advance into the depth having a constant speed and feed rate. This facilitates the recording of released strains in each step of the IHD process. Moreover, despite rotational motion of the drill bit, there is the possibility of stopping the machine feed rate during the IHD operation in each depthincrement in hole-depth. Therefore, during the IHD process, a break time is considered after each incremental depth machined to strain relaxation and recorded the strain data.

\subsection{Hole-Drilling experiment}

The IHD experiment of the FML specimens by high speed drilling machine is performed without fraying, cracking, delamination or separating between the layers, and with no resin burning in the hole-edge. Drilling experiment is performed in three steps and after each drilling step, enough time to the heat transfer (resulted from the IHD process) to be considered in order that thermal strains do not affect the recorded strains values. Two important approaches have been considered in this research.

1- After any increment of hole drilling, the adequate time for strain relaxation and cooling specimens have been provided.

2- In the Wheatstone bridge circuit for measuring released strains, the circuit of temperature compensation has been designed.

In this study, drilling time of each step is 20 seconds, and waiting time (time required for releasing the strain values of each drilling step) between the successive drilling steps is adjusted to 40 seconds. It is also noteworthy that after of each step of drilling, the drill bit be retracted from the hole and turned off while strain measurements are being recorded. Figs. 9 and 10 show the experimental setup used for IHD test of FML 
specimens. Also drilled hole in strain gauge rosette after the IHD experiment is shown in Fig. 11.

\subsection{Strain Measurements}

The IHD experiment used for the FML specimens cause to releasing of trapped strains at the center of the rosette. Under load, these released strains are recorded at each load increment by the three element strain gauge rosette and converted to the residual stresses using the calibration coefficients matrix. Ghasemi et al. [21-22] found out that the number of increment for each ply is dependent to the drilling speed, material properties and thickness of each layer. They realized that one increment for each layer is adequate. They mentioned that one increment for each layer doesn't have considerable error for calculation of the residual stresses in laminated composite materials.

Due to the symmetry lay-ups of the specimens used in this study, the hole-depth is equal to the half of the specimen thickness and the IHD operation is continued up to the symmetry plane of the specimens. The diameter of the hole is $2 \mathrm{~mm}$ and each increment in hole-depth is $0.4 \mathrm{~mm}$. In the first step, the drilling of aluminium ply, in the second step the drilling of two plies of composite with fiber orientation $0^{\circ}$, and in the third step the drilling of two plies of composite with fiber orientation $90^{\circ}$ are performed. The results of the released strains in the IHD procedure of the FML specimen are shown in Fig.12.

In Fig.12, steps 1, 3 and 5 represent the IHD procedure in which the drill bit advances through layers, and steps 2, 4 and 6 are the strain relaxation times in which the drill bit has stopped. As shown in Fig.12, during the IHD process, released strains are variable, but in the time of strain releasing, recorded strains have reached to a relatively stable values and variations become damped. During the IHD experiment of the FML specimen with symmetric lay-up, Gauge\#1 (attached in zero direction), recorded a decreasing strain at first drilled step (aluminium layer) in which continue increased to a positive value at second drilled step (two composite layers with fiber orientation $0^{\circ}$ ). Subsequently, the released strains decreased negative value at third drilled step (two composite layers with fiber orientation $90^{\circ}$ ). The Gauge\#2 (attached in $45^{\circ}$ direction) recorded a decreasing strain at the first drilled step. Also, with increasing in the holedepth at second and third step, the value of the released strains increased. However, the Gauge\#2, at all steps of drilling has negative values of released strains. The Gauge\#3 
(attached in $90^{\circ}$ direction) has a different process. The Gauge\#3 recorded a decreasing strain at the first and second drilled steps. Also, with increasing in the hole-depth at the third step, the value of the released strains increased. The Gauge\#3 during steps 1 and 2 recorded negative released strains; however in the step 3 recorded positive released strains. The average values of released strain after each drilling step of the FML specimen with a stacking sequence of $\left[\mathrm{AL} / 0_{2}^{\circ} / 90_{2}^{\circ}\right]_{\mathrm{S}}$ are reported in Table 3 . Data presented in the Table 3 will later be used to calculate the residual stresses in each holedepth increment.

\section{Results and discussion}

Because of the ability for speed control of high speed drilling machine (constant speed and feed rate), and the absence of externally applied load to the specimen during the IHD experiment, measured strain from the IHD test of the FML specimens is reliable and can be evaluated by the theoretical results from the CLT method. In the following, the CLT method is presented to determine the theoretical values of the residual stresses.

\subsection{Classical laminate theory}

Residual stresses at the macroscopic level could be estimated using the CLT [21,33] by assuming plane stress condition and linear elastic behavior for each ply. Fig. 13 shows the flow-chart including all the data inputs needed by the algorithm. A brief review of the CLT formulation for the calculation of macro-residual stresses in laminated composites is presented as follow:

1- Calculate thermal strains $\left\{\varepsilon_{t h}\right\} \begin{array}{ll}(k) & \text { off }\end{array}$

$$
\left\{\varepsilon_{t h}\right\} \quad \begin{aligned}
& (k) \\
& \text { off }
\end{aligned}=\{\alpha\}_{\text {off }}^{(k)} \Delta T=\left[\begin{array}{ccc}
m^{2} & n^{2} & -m n \\
n^{2} & m^{2} & m n \\
2 m n & -2 m n & m^{2}-n^{2}
\end{array}\right]^{(k)}\left\{\begin{array}{c}
\alpha_{x} \\
\alpha_{y} \\
0
\end{array}\right\} \Delta T
$$

where $m=\cos (\theta)$ and $n=\sin (\theta) . \Delta T$ is the temperature difference, $\{\alpha\}_{\mathrm{off}}^{(k)}$ is the vector of CTE in the off-axis direction, $[T]{ }^{(k)}$ is the transformation matrices and $k$ is the layer number.

2- Calculate thermal resultants loads $\left\{N^{T}\right\}$ and moments $\left\{M^{T}\right\}$ : 


$$
\begin{aligned}
& \left(N_{1}^{T}, M_{1}^{T}\right)=\sum_{k=1}^{n}\left(\bar{Q}_{11}^{(k)} \alpha_{1}^{(k)}+\bar{Q}_{12}^{(k)} \alpha_{2}^{(k)}+\bar{Q}_{16}^{(k)} \alpha_{6}^{(k)}\right) \Delta T\left(t_{k}, t_{k} z_{k}\right) \\
& \left(N_{2}^{T}, M_{2}^{T}\right)=\sum_{k=1}^{n}\left(\bar{Q}_{21}^{(k)} \alpha_{1}^{(k)}+\bar{Q}_{22}^{(k)} \alpha_{2}^{(k)}+\bar{Q}_{26}^{(k)} \alpha_{6}^{(k)}\right) \Delta T\left(t_{k}, t_{k} z_{k}\right) \\
& \left(N_{6}^{T}, M_{6}^{T}\right)=\sum_{k=1}^{n}\left(\bar{Q}_{61}^{(k)} \alpha_{1}^{(k)}+\bar{Q}_{62}^{(k)} \alpha_{2}^{(k)}+\bar{Q}_{66}^{(k)} \alpha_{6}^{(k)}\right) \Delta T\left(t_{k}, t_{k} z_{k}\right)
\end{aligned}
$$

Where $\left[\bar{Q}_{i j}\right]^{(k)}$ is the reduced transformation in off-axis direction. $t_{k}$ and $z_{k}$ are the ply thickness of the $k$ th lamina and distance to the reference plane, respectively.

3- Calculate the laminate stiffness matrices $[A],[B]$ and $[D]$ :

$$
\left[A_{i j}, B_{i j}, D_{i j}\right]=\sum_{k=1}^{n} \int_{z_{k-1}}^{z_{k}}\left[\bar{Q}_{i j}\right]^{(k)}\left(1, z, z^{2}\right) d z
$$

where, $A_{i j}, B_{i j}$ and $D_{i j}$ are extensional, coupling and bending stiffness matrices, respectively.

4- Calculate the laminate mid-plane strains $\left\{\varepsilon^{\circ}\right\}$ and curvatures $\{\kappa\}$ :

$\left\{\begin{array}{c}\varepsilon^{\circ} \\ \kappa\end{array}\right\}=\left[\begin{array}{ll}A & B \\ B & D\end{array}\right]^{-1}\left\{\begin{array}{l}N^{T} \\ M^{T}\end{array}\right\}$

The $A B D$ matrix is a $6 \times 6$ matrix that serves as a connection between the applied loads and the mid-plane strains in the laminate.

5- Calculate the residual strains vector $\left\{\varepsilon_{r s}\right\}_{\text {off }}^{(k)}$ using the difference between the thermal strains and the mechanical strains. Also, the residual stresses vector $\left\{\sigma_{r s}\right\}_{\text {off }}^{(k)}$ for each ply is obtained as follows:

$$
\begin{aligned}
& \left\{\varepsilon_{r s}\right\}_{\text {off }}^{(k)}=\left\{\varepsilon_{n e t}\right\} \quad \begin{array}{ll}
(k) \\
\text { off }
\end{array}-\left\{\varepsilon_{t h}\right\} \quad \begin{array}{l}
(k) \\
\text { off }
\end{array}=\left(\left\{\begin{array}{c}
\varepsilon_{1}^{\circ} \\
\varepsilon_{2}^{\circ} \\
\varepsilon_{6}
\end{array}\right\}+z_{k}\left\{\begin{array}{l}
\kappa_{1} \\
\kappa_{2} \\
\kappa_{6}
\end{array}\right\}\right)-\left(\left\{\begin{array}{l}
\alpha_{1} \\
\alpha_{2} \\
\alpha_{6}
\end{array}\right\}^{(k)} \Delta T\right) \\
& \left\{\sigma_{r s}\right\}_{\text {off }}^{(k)}=\left[\bar{Q}_{i j}\right]^{(k)}\left\{\varepsilon_{r s}\right\}_{\text {off }}^{(k)}
\end{aligned}
$$

\subsection{Residual stresses evaluation}

In the previous section, MATLAB software was used to write a computer program for calculating the theoretical values of the residual stresses by the CLT method. In this 
program, information regarding number $(\mathrm{n})$, orientation $(\theta)$ and thickness $(\mathrm{t})$ of plies, and their properties are read from an input file (see Fig. 13). Also, the experimental values of the residual stress measurement by the IHD process are obtained using calibration coefficients matrix presented in Eq. (16), and the average of measured strains in each step of drilling experiment are presented in Table 3. In this section, the experimental data from the IHD process are compared with the theoretical prediction of the CLT method.

Comparison between the results of stress component $\sigma_{x}$ from the CLT method and experimentally obtained values of each step of the IHD process is shown in Fig. 14. In the first hole-depth increment, where strain gauge rosette is mounted on the surface of test specimen, a good agreement between the experimental and theoretical results is obtained. With an increase in the hole-depth increment, the error percentage grows in a way that maximum error value is observed in the third increment in hole-depth (plies with orientation $90^{\circ}$ ). The difference between theoretical and experimental values of the stress component $\sigma_{x}$ in this step is $1.46 \mathrm{MPa}$. Fig. 15 shows the theoretical and experimental values of the stress component $\sigma_{x y}$. The CLT method predicted the values of shear residual stress in symmetric cross-ply laminates as zero. The results from the measurement of the residual stress based on the IHD experiments are also small values. The maximum measured shear stress of $\left[\mathrm{AL} / 0_{2}^{\circ} / 90_{2}^{\circ}\right]_{\mathrm{S}}$ laminates is equal to $0.6 \mathrm{MPa}$ which is negligible in comparison to its theoretical values based on the CLT method. Fig. 16 shows the theoretical prediction and experimental data of stress component $\sigma_{y}$. As depicted in the Fig. 16, the experimental results of the IHD tests correspond well with the theoretical results of the CLT method. The maximum observed error value is $15.7 \%$ and occurred in the second drilled hole-depth increment (plies with orientation $0^{\circ}$ ). The mismatch between theoretical and experimental values of stress component $\sigma_{y}$ in this step is $0.89 \mathrm{MPa}$. It should be mentioned that due to the thickness of Al layer and thickness of ply in laminated composite, the depth must be increased to $1.2 \mathrm{~mm}$ as considered in the Figs. 14-16. Although the error has been increased in the third step, this depth of drilling is less than the hole diameter which is according to the ASTM standard. Also, it is depicted that with increasing the depth, the errors in the third step are more than the first and second steps. 
Evaluation of the Residual stresses in FML composite with symmetric stacking sequence of $\left[\mathrm{AL} / 0_{2}^{\circ} / 90_{2}^{\circ}\right]_{\mathrm{S}}$ is presented in Table 4 . The results of Table 4 can be summarized as follows:

1- Interpretation of theoretical results of the CLT method, takes into consideration the satisfaction of the equilibrium condition of the residual stresses through the thickness of the laminate. To satisfy the equilibrium of the residual stresses, it is necessary that the summation of the stress components in all directions and through the thickness of the laminate is zero. According to the obtained experimental results, the summation of $\sigma_{x}, \sigma_{y}$ and $\sigma_{x y}$ stress components in $\mathrm{x}, \mathrm{y}$, and xy-directions and through the thickness of the laminate, are $0.10,0.12$, and $0.65 \mathrm{MPa}$, respectively. These values are close to the theoretical values which are zero according to the CLT method.

2-It is also found that the accuracy of the experimental data of the IHD experiment is adequate when starting the drilling operation; but with an increase in the hole-depth, the accuracy of results is reduced somewhat. The most important factor that differentiates between experimental and theoretical results is the reduction of released strain values on the surface of specimen recorded by strain gauge rosette. According to the Table 4, with consideration some parameters as manufacture (time curing and cooling), simulation (size of meshand type of elements), and test (circuit of temperature compensation and time of strain relaxation), the results have been obtained the less errors for some steps. Also, the stress-measurement errors have been obtained in the 10-20-percent range. Because the rosette is mounted on the specimen's surface and the released strains on the parts surface are read, while the non-uniform residual stresses are through the thickness of specimen. This difference in the locations of the stresses and the measured strains creates a limitation for increasing the hole-depth. According to the ASTM-E837 [11] for uniform residual stresses, drilling process can advance up to depth 0.8 multiple of rosette's diameter and also to non-uniform residual stresses this value is $0.3-0.4$ multiple of rosette's radius.

\section{Conclusions}

In this paper, the IHD technique was used to measure experimentally non-uniform residual stresses in each ply of the FML composites by the integral method. At the first, the calibration coefficients matrix was calculated to relate the residual stresses and 
relieved strains, using the FE simulation. Then, by performing the IHD experiment, released strains in the FML specimens with stacking sequence of $\left[\mathrm{AL} / 0_{2}^{\circ} / 90_{2}^{\circ}\right]_{\mathrm{S}}$ were measured. In the following, the residual stresses were obtained using the calibration coefficients matrix and measured strains in each step of the IHD experiment. Finally, the experimental data from the IHD process were evaluated by the theoretical predictions of the CLT method. The results obtained from both the IHD and CLT methods indicated that the accuracy of experimental results was adequate when starting the drilling operation. The maximum difference between both methods in the first step of drilling was $3.1 \%$. But with an increase in the hole-depth, the accuracy of the experimental results was reduced. One of the factors which differentiate between obtained results was the reduction of released strain values on the surface of the FML specimen recorded by the strain gauge rosette with an increase in the hole-depth, and reduces the amount of released strains from accuracy level of data logger device. Good match between experimental results from recent study with the theoretical ones validates the use of IHD method as a powerful technique to evaluation of non-uniform residual stresses in the FML composites.

\section{Acknowledgments}

The authors are grateful to the Iran National Science Foundation (INSF) for supporting this work.

\section{References}

[1] Sinmazçelik T, Avcu E, Bora MÖ, Çoban O. A review: Fibre metal laminates, background, bonding types and applied test methods. Materials \& Design 2011; 32(7): 3671-3685.

[2] Hu YB, Li HG, Cai L, Zhu JP, Pan L, Xu J, Tao J. Preparation and properties of FibreMetal Laminates based on carbon fibre reinforced PMR polyimide. Composites Part B: Engineering 2015; 69: 587-591.

[3] Pawar OA, Gaikhe YS, Tewari A, Sundaram R, Joshi SS. Analysis of hole-quality in drilling GLARE fiber metal laminates. Composite Structures 2015; 123: 350-365. 
[4] Carrillo JG, Cantwell WJ. Mechanical properties of a novel fiber-metal laminate based on a polypropylene composite. Mechanics of Materials 2009; 41(7): 828-838.

[5] Şen I, Alderliesten RC, Benedictus R. Lay-up optimisation of fibre metal laminates based on fatigue crack propagation and residual strength. Composite Structures 2015; 124: 77-87.

[6] Chai GB, Manikandan P. Low velocity impact response of fibre-metal laminates-A review. Composite Structures 2014; 107: 363-381.

[7] Lee BE, Park ET, Kim J, Kang BS, Song WJ. Analytical evaluation on uniaxial tensile deformation behavior of fiber metal laminate based on SRPP and its experimental confirmation. Composites Part B: Engineering 2014; 67: 154-159.

[8] Hausmann J, Naghipour P, Schulze K. Analytical and numerical residual stress models for fiber metal laminates-comparison and application. Procedia Materials Science 2013; 2: 68-73.

[9] Albedah A, Bouiadjra BB, Aminallah L, Es-Saheb M, Benyahia F. Numerical analysis of the effect of thermal residual stresses on the performances of bonded composite repairs in aircraft structures. Composites Part B: Engineering 2011; 42(3): 511516.

[10] Telford R, Katnam KB, Young TM. Analysing thermally induced macro-scale residual stresses in tailored morphing composite laminates. Composite Structures 2014; 117: 40-50.

[11] Determining residual stresses by the hole-drilling strain-gage method. ASTM Standard test method E837-08. American Society for Testing and Materials. West Conshohocken; 2008.

[12] Rossini NS, Dassisti M, Benyounis KY, Olabi AG. Methods of measuring residual stresses in components. Materials \& Design 2012; 35: 572-588.

[13] Schajer GS. Measurement of Non-Uniform Residual Stresses Using the Hole-Drilling Method. Part I - Stress Calculation Procedures. Journal of Engineering Materials \& Technology 1988; 110: 338-344. 
[14] Schajer GS. Measurement of Non-Uniform Residual Stresses Using the Hole-Drilling Method. Part II- Practical Application of the Integral Method. Journal of Engineering Materials \& Technology 1988; 110:345-349.

[15] Flaman MT, Mills BE, Boag JM. Analysis of Stress-Variation With-Depth Measurements Procedures for the Center-Hole Method of Residual Stress Measurement. Experimental Techniques, 1987; 11(6): 35-37.

[16] Flaman MT, Herring JA. Comparison of Four Hole-Producing Techniques for the Center-Hole Residual-Stress Measurement Method. Journal of Experimental Techniques 1985; 9(8): 30-33.

[17] Flaman MT, Boag JM. Comparison of Residual-Stress Variation with Depth-Analysis Techniques for the Hole- Drilling Method. Experimental Techniques 1990; 30(4): 352-355.

[18] Sicot O, Gong XL, Cherouat A, Lu J. Determination of Residual Stress in Composite Laminates Using the Incremental Hole-Drilling Method. Journal of Composite Materials 2003; 37(9): 831-843.

[19] Sicot O, Gong XL, Cherouat A, Lu J. Influence of Experimental Parameters on Determination of Residual Stress Using the Incremental Hole-Drilling Method. Journal of Composite Science \& Technology 2004; 64(2): 171-180.

[20] Pagliaro P, Zuccarello B. Residual stress analysis of orthotropic materials by the through-hole drilling method. Experimental Mechanics 2007; 47(2); 217-236.

[21] Ghasemi AR, Taheri-Behrooz F, Shokrieh MM. Determination of non-uniform residual stresses in laminated composites using integral hole drilling method: Experimental evaluation. Journal of Composite Materials 2014; 48(4): 415-425.

[22] Ghasemi AR, Taheri-Behrooz F, Shokrieh MM. Measuring residual stresses in composite materials using the simulated hole-drilling method." Residual Stresses in Composite Materials (2014): 76.

[23] Shokrieh MM, Ghasemi AR. Simulation of central hole drilling process for measurement of residual stresses in isotropic, orthotropic, and laminated composite plates. Journal of Composite Materials 2007; 41(4): 435-452. 
[24] Shokrieh MM, Ghasemi AR. Determination of calibration factors of the hole drilling method for orthotropic composites using an exact solution. Journal of composite materials 2007; 41(19): 2293-2311.

[25] Schajer GS, Yang L. Residual-stress measurement in orthotropic materials using the hole-drilling method. Experimental Mechanics 1994, 34(4): 324-333.

[26] Andersen L F. Experimental Method for Residual Stress Evaluation Through the Thickness of a Plate. Journal of Engineering Materials \& Technology 2002; 124(4): 428-433.

[27] Ghasemi AR, Shokrieh MM. Development of an Integral Method for Determination of Non-uniform Residual Stresses in Laminated Composites. Journal of Polymer Science and Technology 2008; 21(4): 347-355.

[28] Ghasemi AR, Shokrieh MM. Residual Strains Measurement and Calculating Residual Stresses in Composite Laminates Using Integral Method. Journal of Computational Methods in Engineering 2010; 28(2): 81-93.

[29] Akbari S, Taheri-Behrooz F, Shokrieh MM. Characterization of residual stresses in a thin-walled filament wound carbon/epoxy ring using incremental hole drilling method. Composites Science and Technology 2014; 94: 8-15.

[30] Schajer GS. Advances in hole-drilling residual stress measurements. Experimental mechanics 2010; 50(2): 159-168.

[31] Stefanescu D, Truman CE, Smith DJ, Whitehead PS. Improvements in residual stress measurement by the incremental centre hole drilling technique. Experimental mechanics 2006; 46(4): 417-427.

[32] Schapery RA. Thermal expansion coefficients of composite materials based on energy principles. Journal of Composite Materials 1968; 2(3): 380-404.

[33] Ghasemi AR, Mohammadi MM, Mohandes M. The Role of Carbon Nanofibers on Thermo-mechanical Properties of Polymer Matrix Composites and Their Effect on Reduction of Residual Stresses. Composites Part B: Engineering 2015; 77: 519-527. 


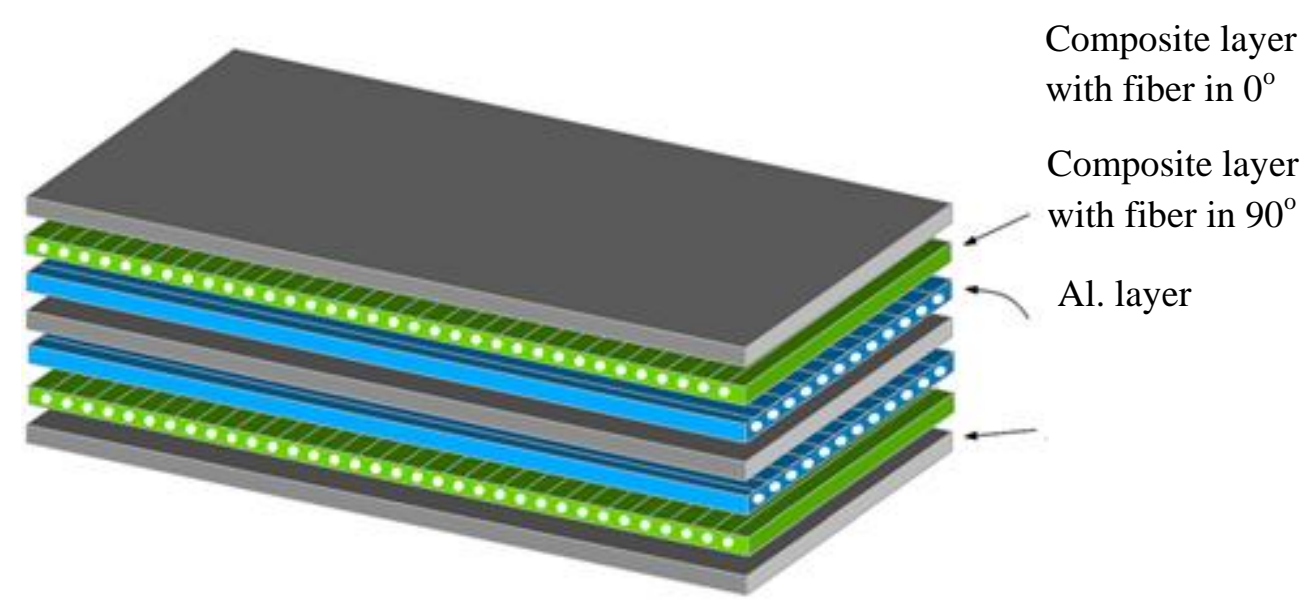

Fig. 1: FML structure with a stacking sequence of $\left[\mathrm{AL} / 0^{\circ} / 90^{\circ}\right]_{\mathrm{S}}$

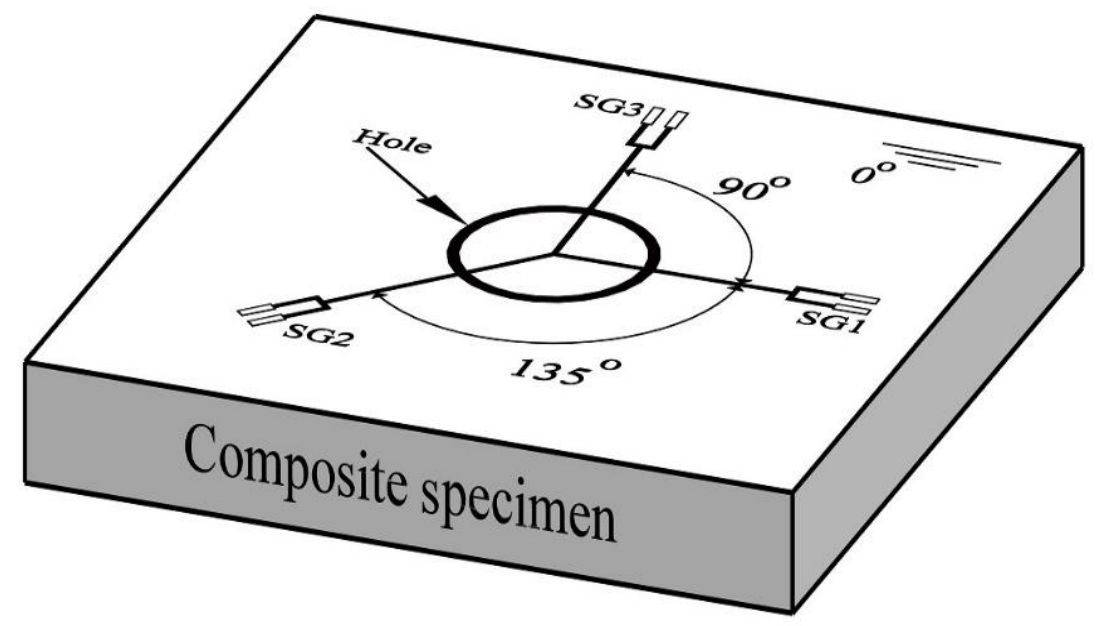

Fig.2: Specimen, hole geometry and position of the strain gauge rosette 


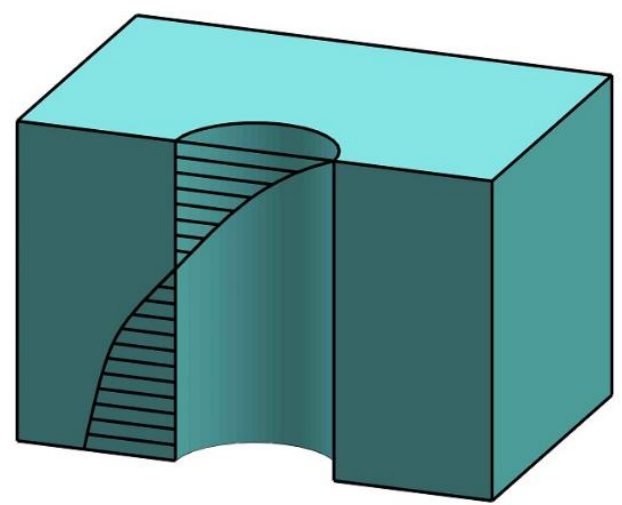

(a)

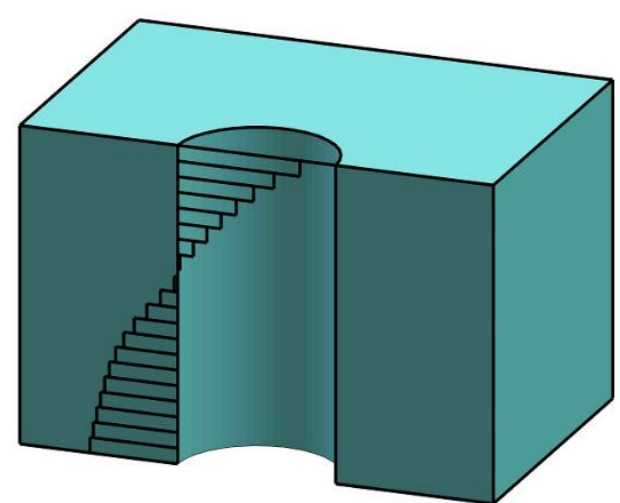

(b)

Fig. 3:a. Arbitrary distribution of residual stresses. b. Distribution of non-uniform residual stresses assumed for the integral method

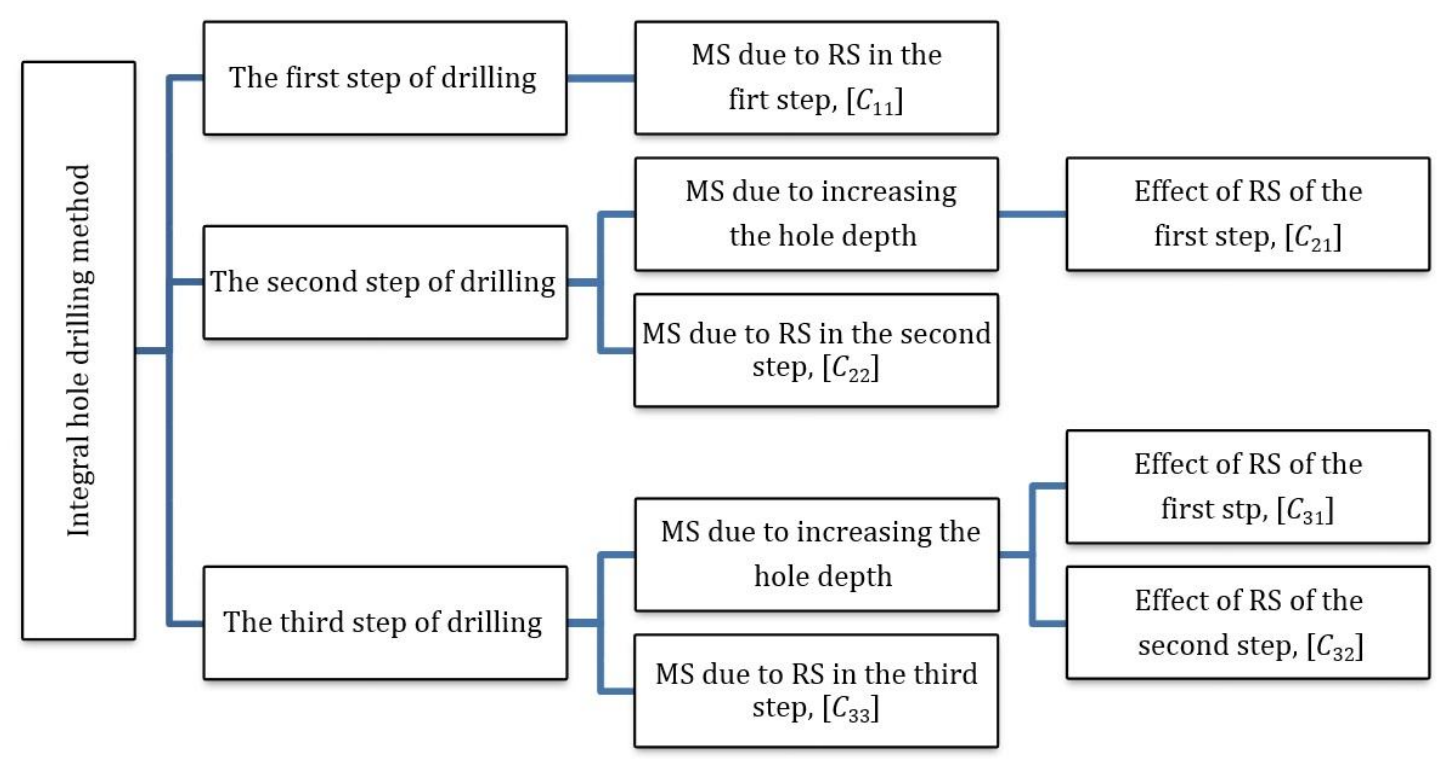

Fig. 4: Relation between MS (measured strains) and RS (residual stresses) in the integral hole drilling method 

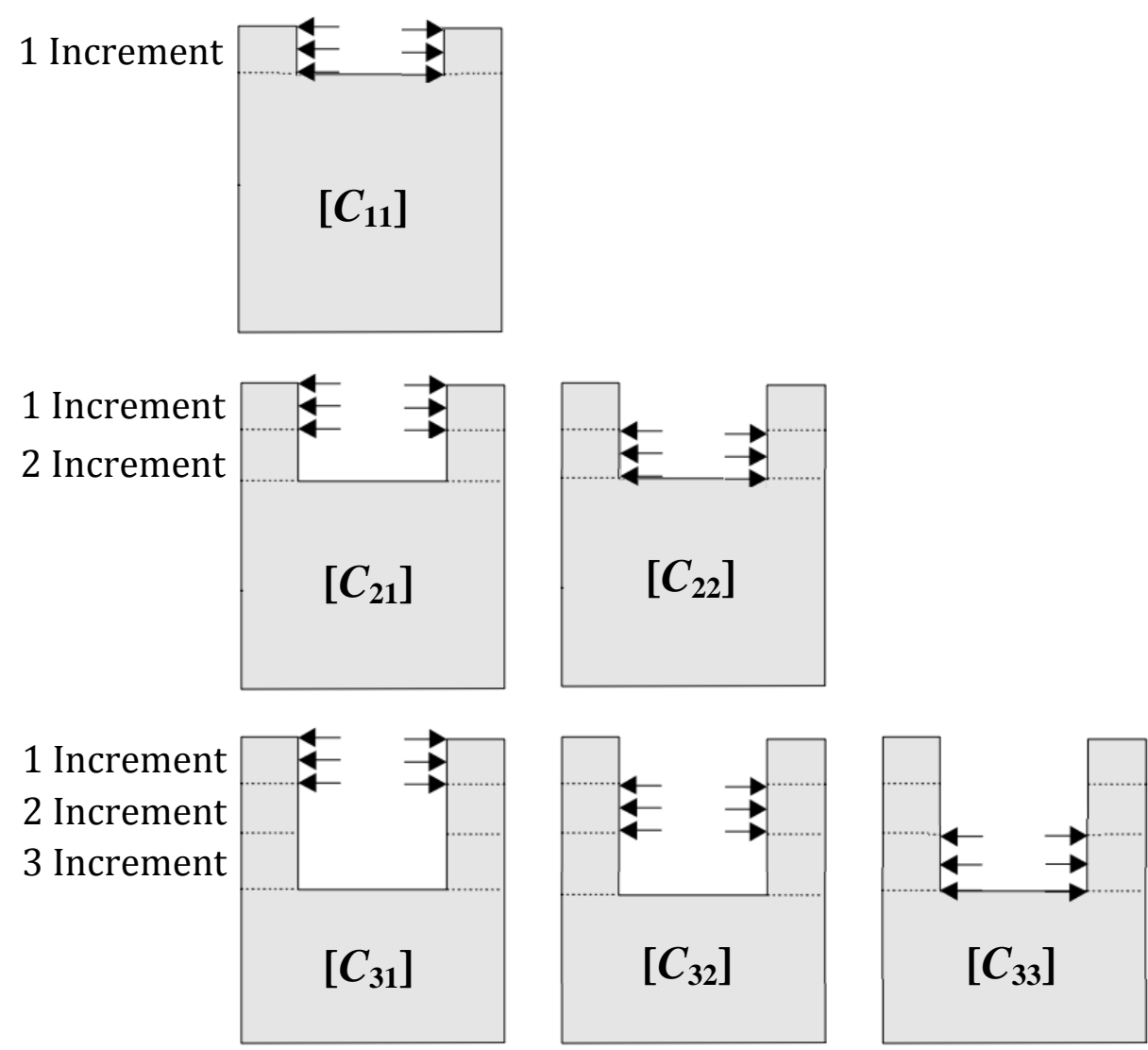

Fig. 5: Stress and hole-depth corresponding to calibration coefficients $\left[C_{i j}\right]$ 


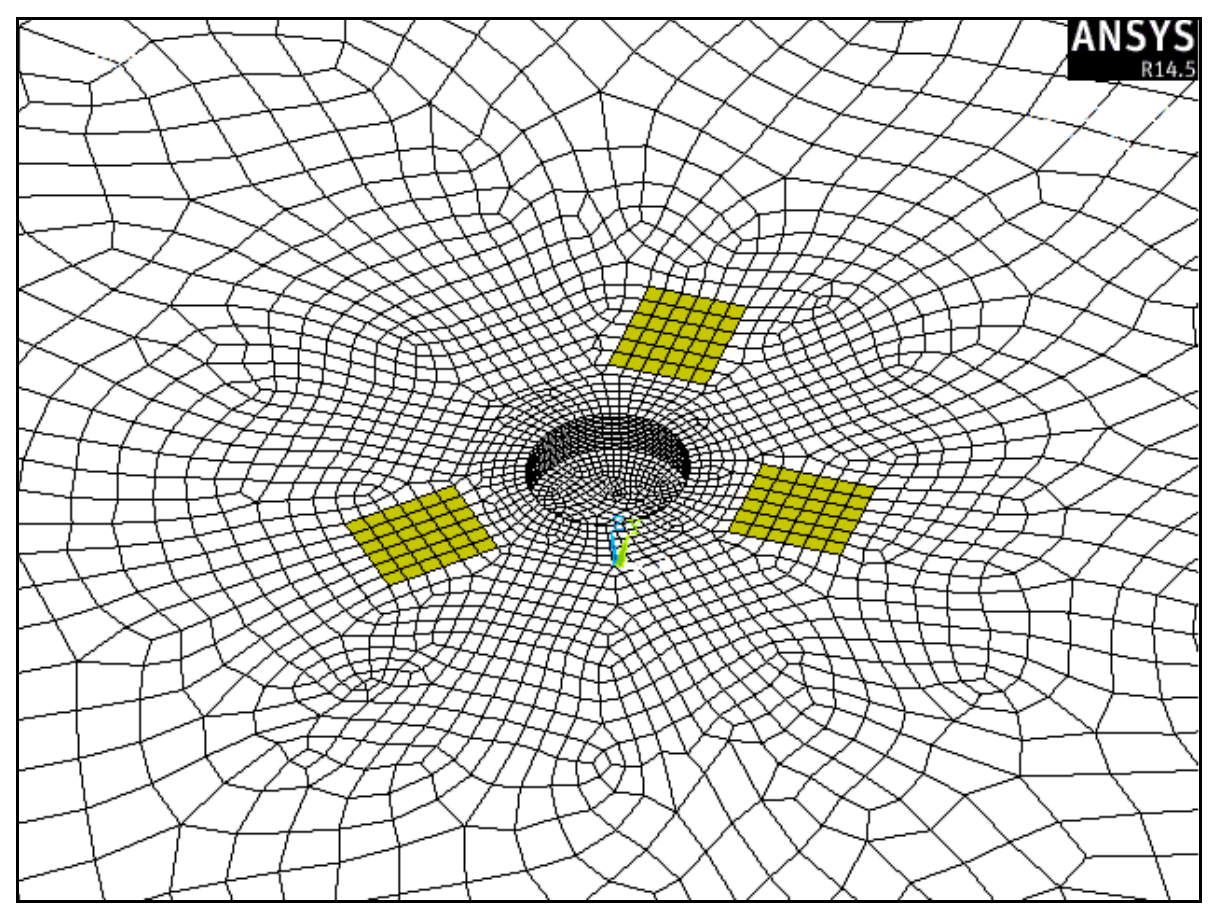

Fig. 6: Simulation model used for the calculation of the calibration coefficients

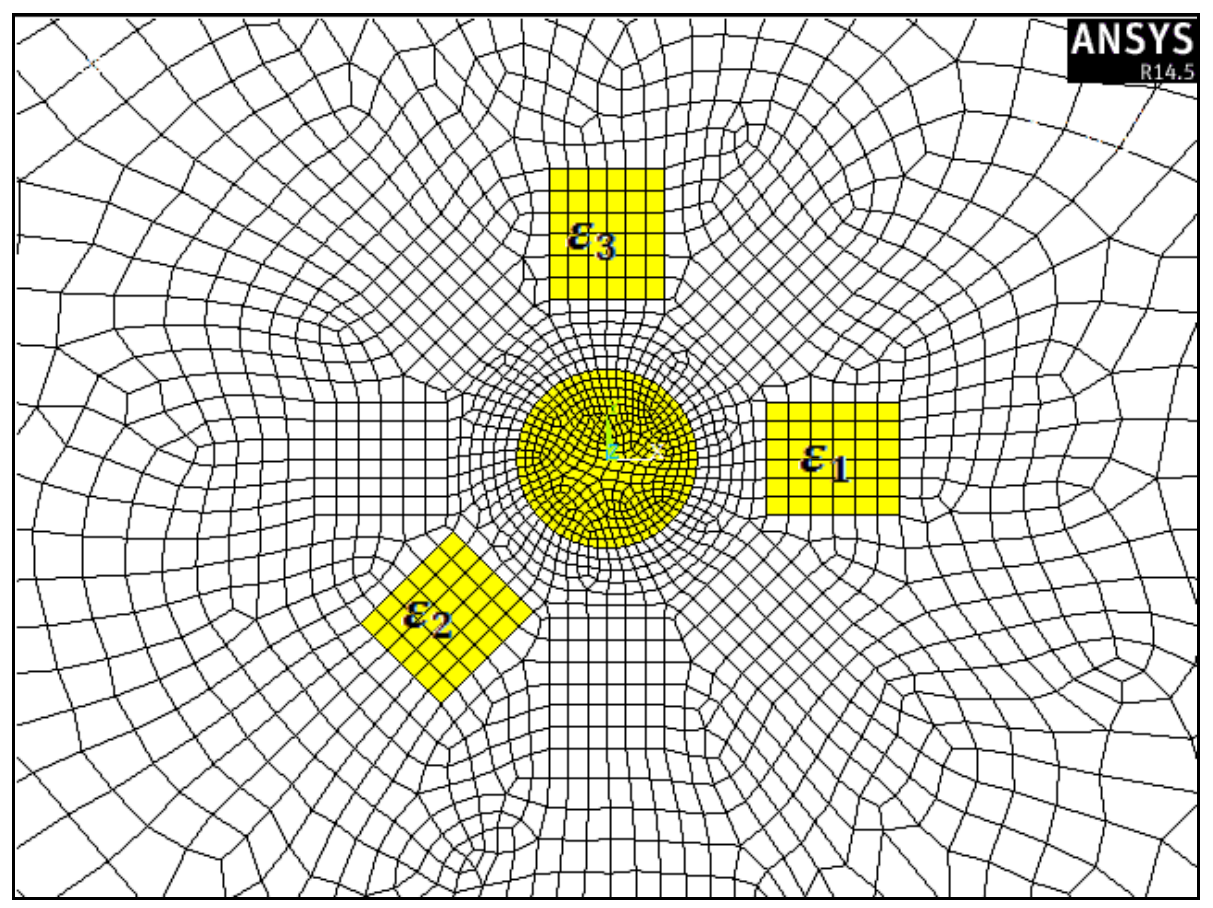

Fig. 7: Simulation model of the strain gauge rosette and the hole geometry 

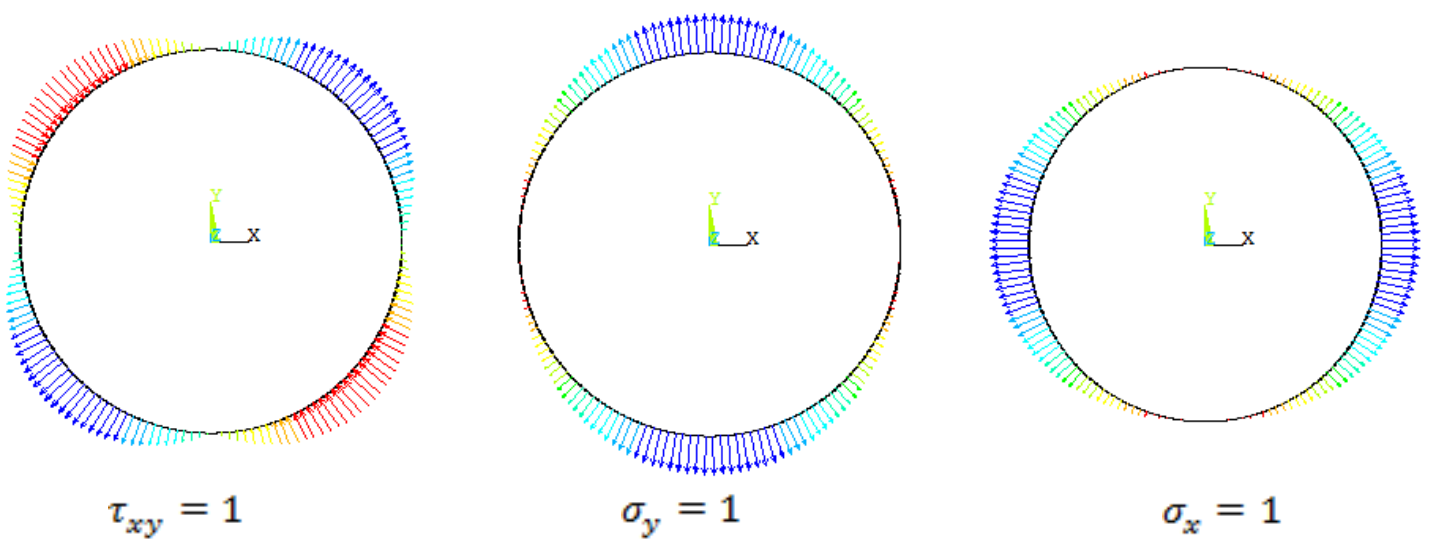

Fig. 8: Basis loading conditions to be applied to the FE model

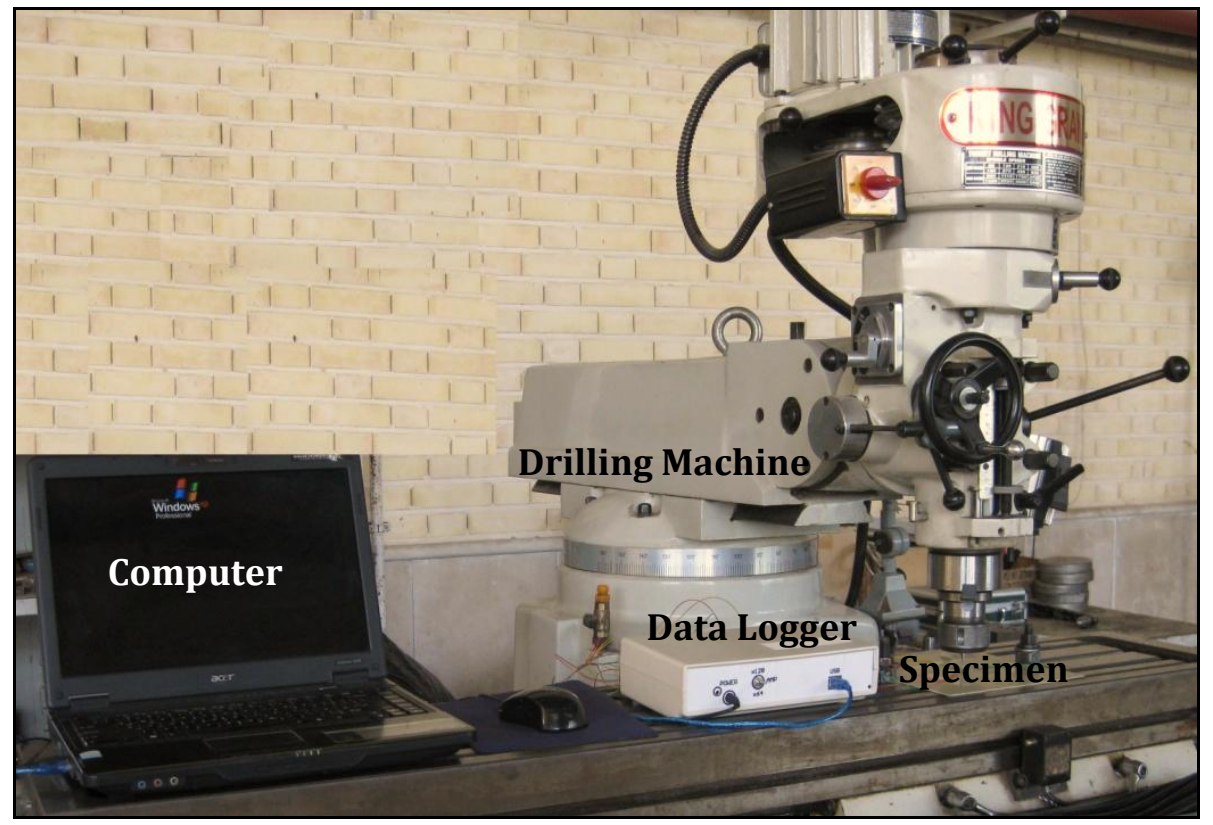

Fig. 9: Experimental setup used for the IHD procedure 


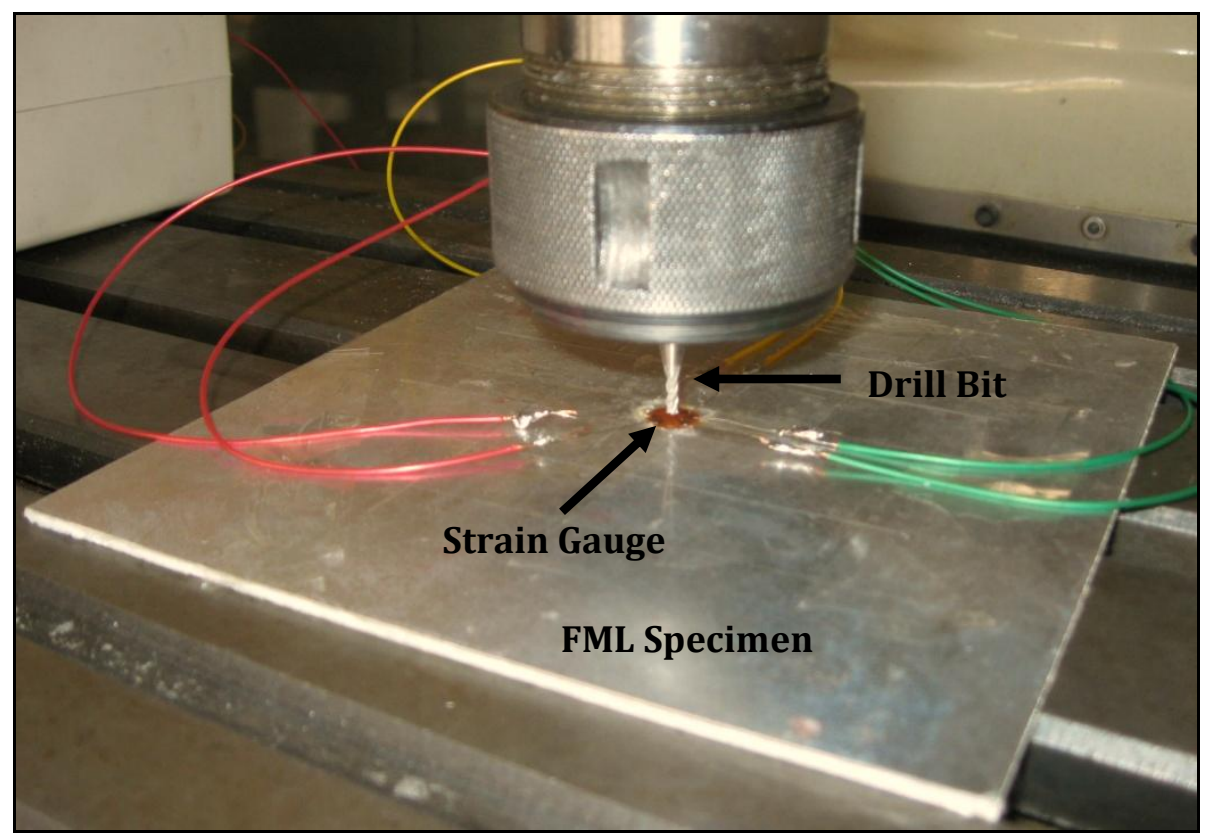

Fig. 10: Specimen under the high speed drilling machine before the IHD experiment

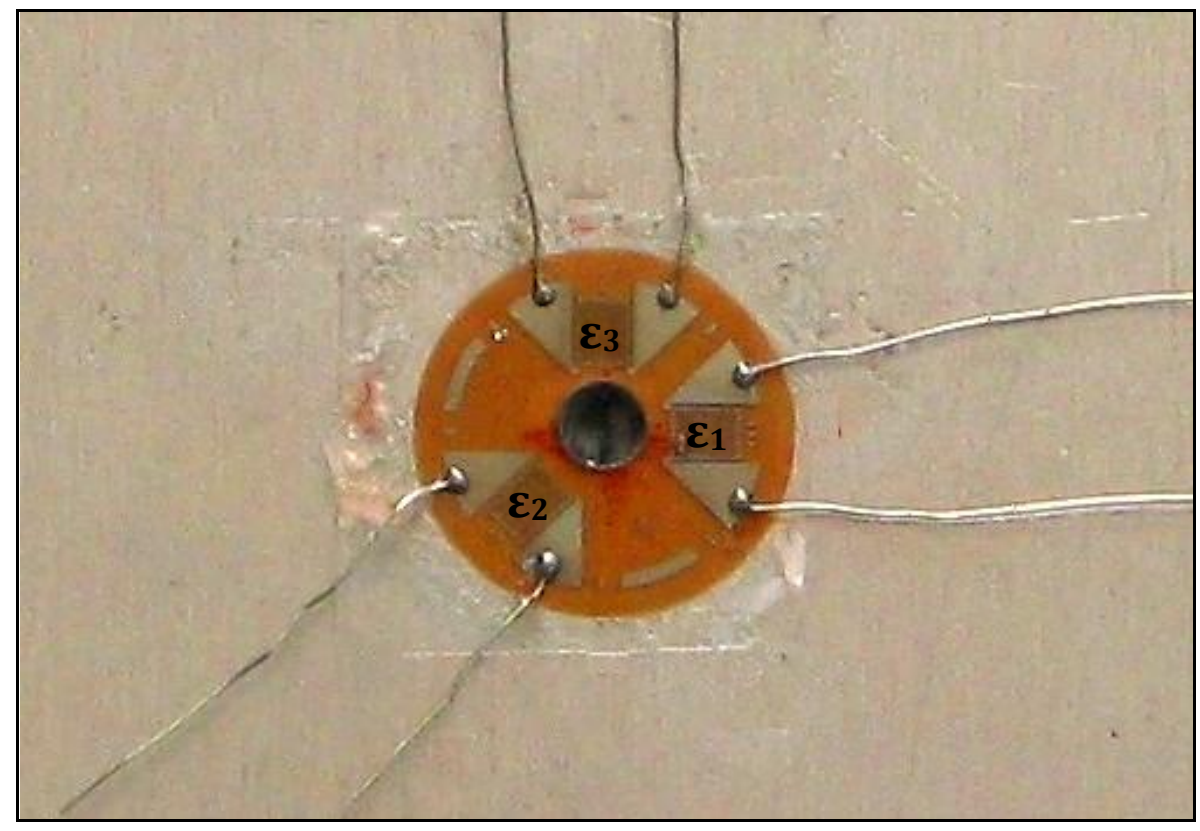

Fig. 11: Drilled hole in strain gauge after the IHD experiment 


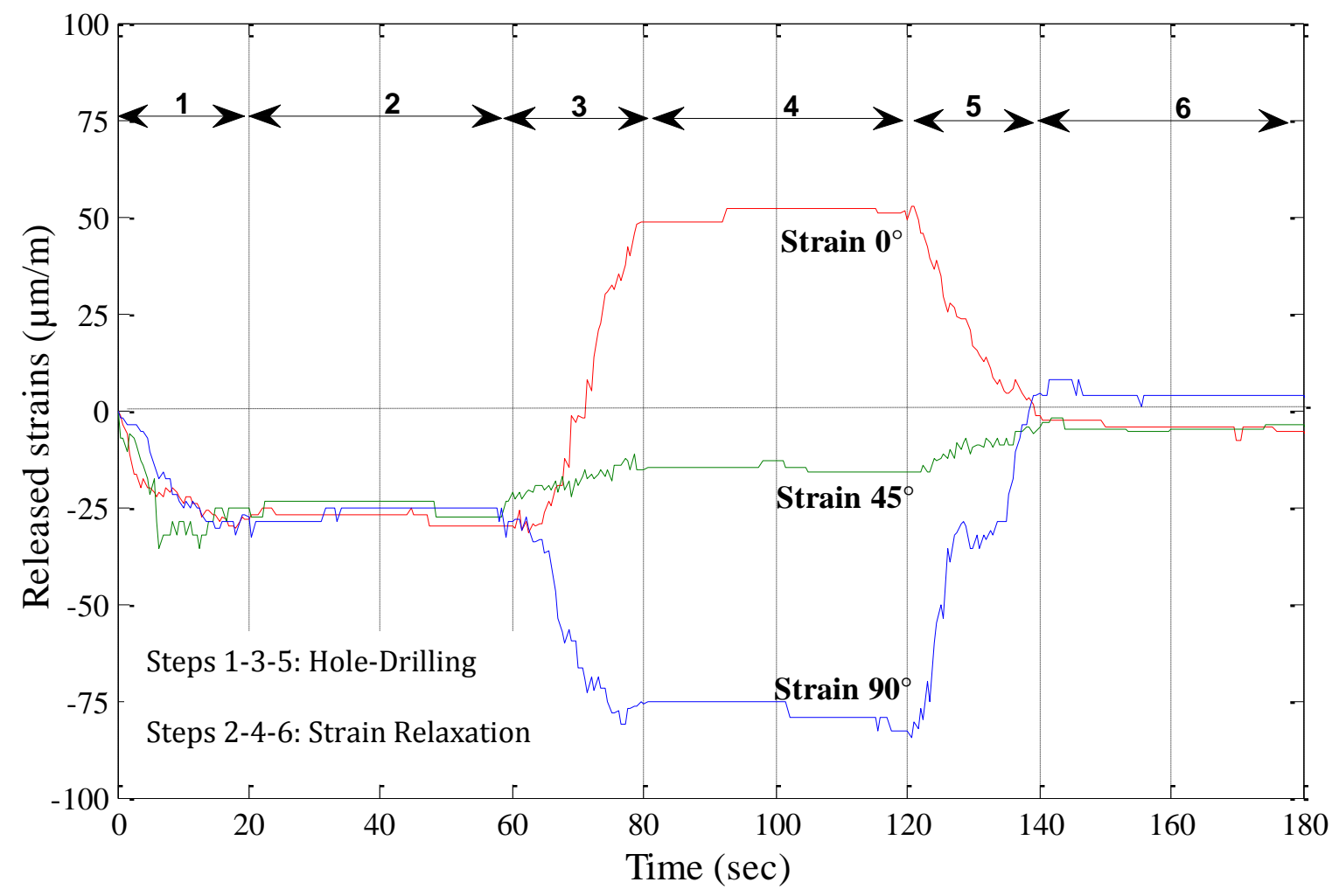

Fig. 12: Measured strains in the IHD experiment 


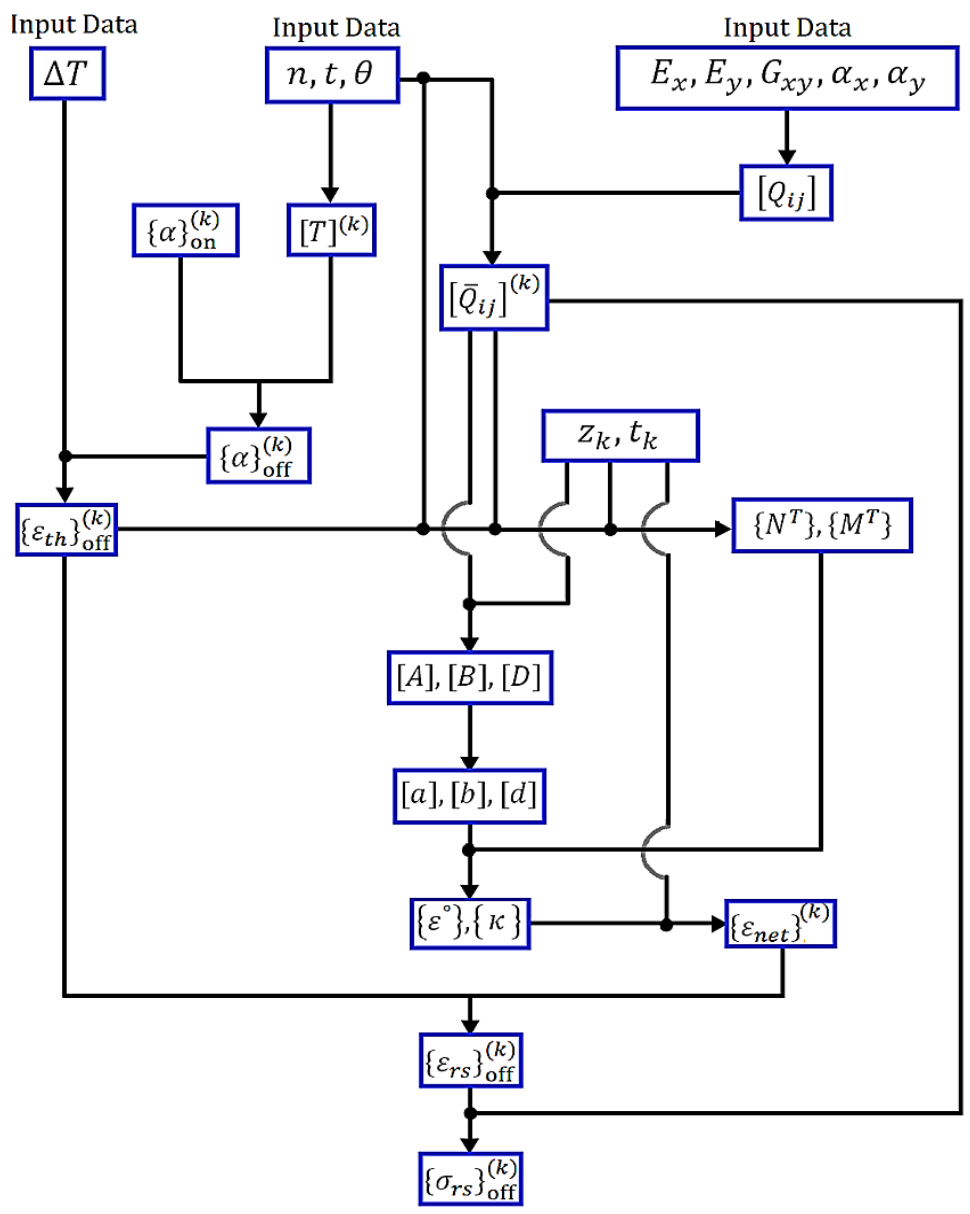

Fig. 13: Classical laminate theory flowchart 


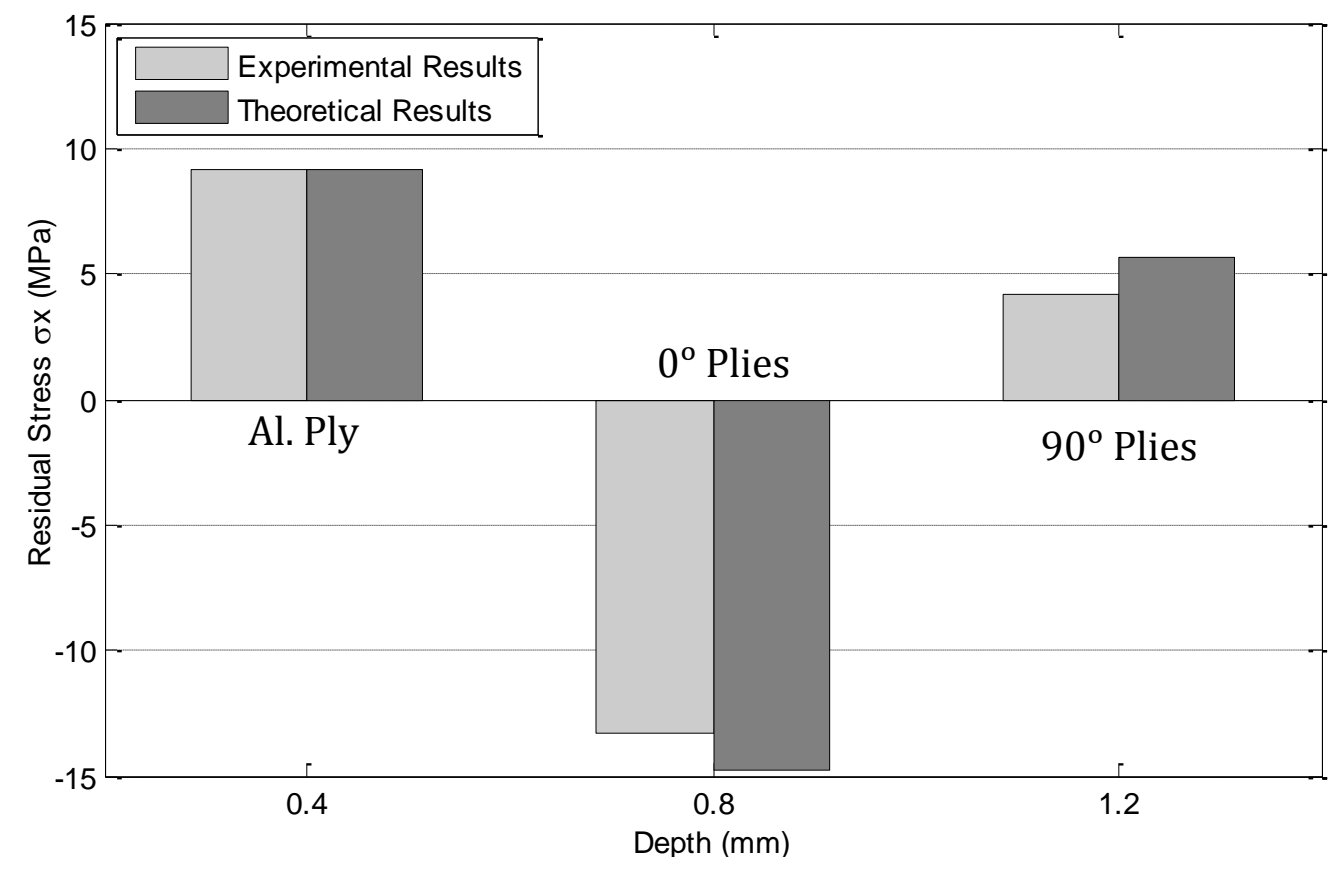

Fig. 14: Experimental and theoretical results of stress components $\sigma_{x}$ for $\left[\mathrm{AL} / \mathrm{O}_{2}^{\circ} / 90_{2}^{\circ}\right]_{\mathrm{S}}$ laminate

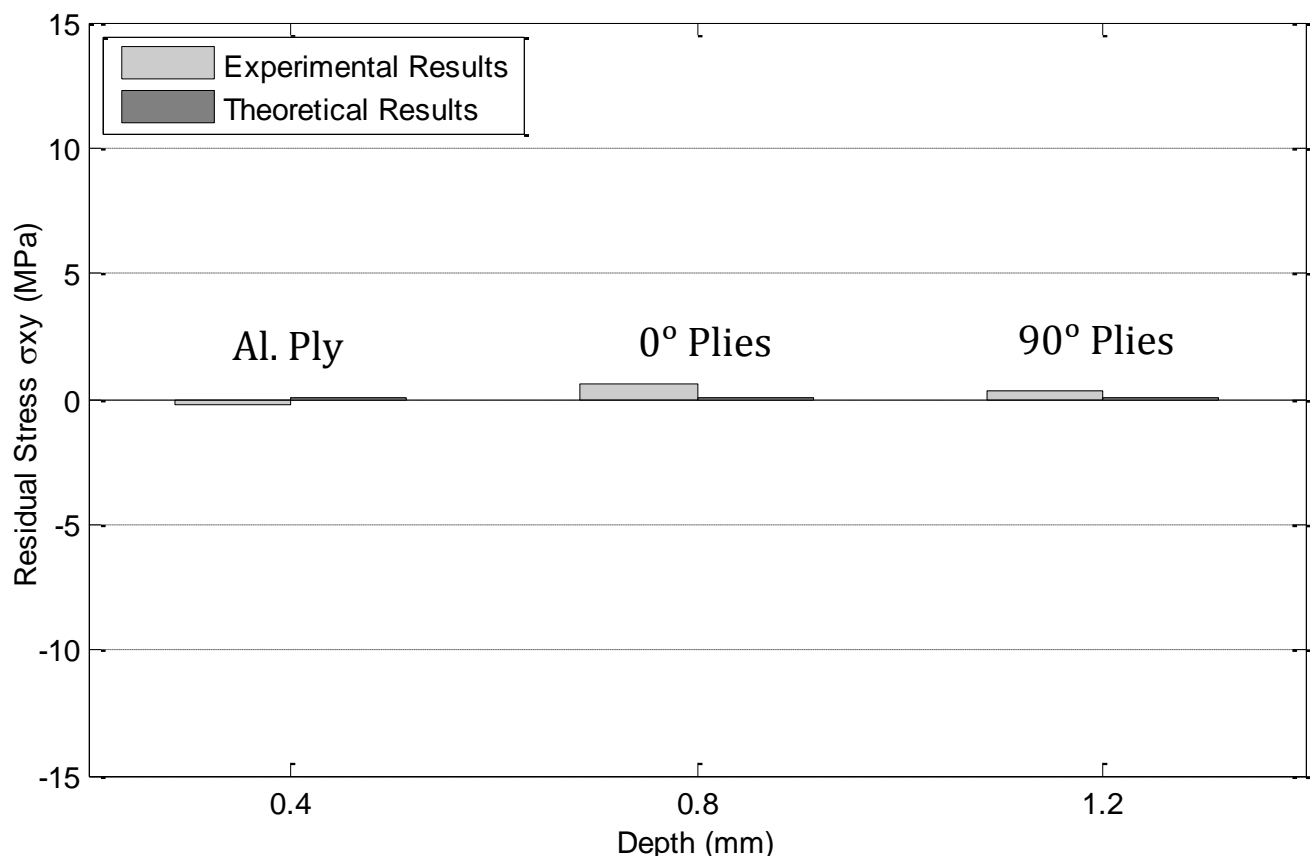

Fig. 15: Experimental and theoretical results of stress components $\sigma_{x y}$ for $\left[\mathrm{AL} / 0_{2}^{\circ} / 90_{2}^{\circ}\right]_{\mathrm{S}}$ laminate 


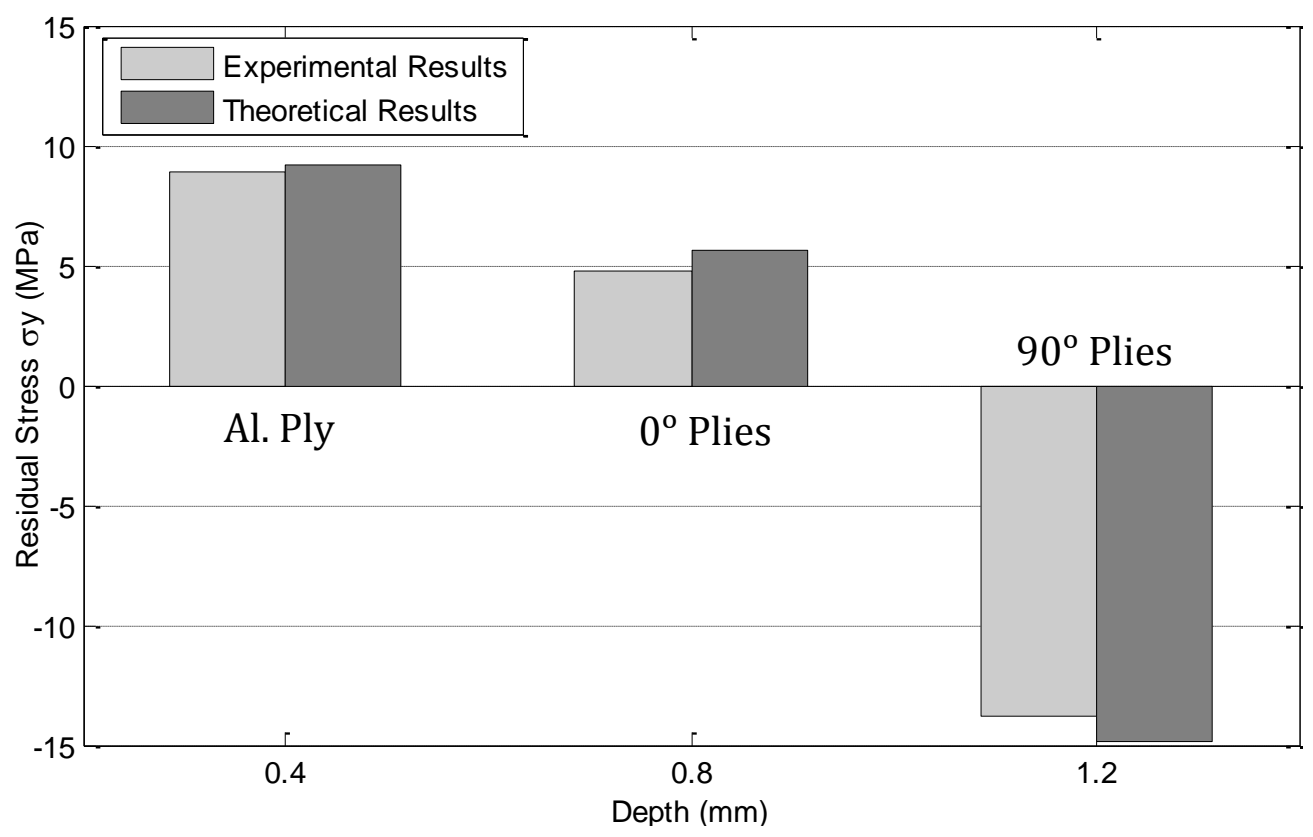

Fig. 16: Experimental and theoretical results of stress components $\sigma_{y}$ for $\left[\mathrm{AL} / \mathrm{O}_{2}^{\circ} / 90_{2}^{\circ}\right]_{\mathrm{S}}$ laminate 
Table 1: Geometry characterization used in the numerical/experimental results

\begin{tabular}{cccccccc}
\hline \multicolumn{2}{c}{ Thickness $(\mathrm{mm})$} & & \multicolumn{2}{c}{ Diameter $(\mathrm{mm})$} & & \multicolumn{2}{c}{ Dimensions $\left(\mathrm{mm}^{2}\right)$} \\
\cline { 1 - 2 } Metal & Composite & & Strain gauge & Hole & & Specimen & Strain gauge \\
\hline 0.4 & 0.2 & & 5.14 & & & $150 \times 150$ & $1.3 \times 1.5$ \\
\hline
\end{tabular}

Table 2: Material properties used in the numerical/experimental results

\begin{tabular}{lcccccc}
\hline Material & $E_{x}(\mathrm{GPa})$ & $E_{y}(\mathrm{GPa})$ & $G_{x y}(\mathrm{GPa})$ & $v_{x y}$ & $\alpha_{x}\left(\mu /{ }^{\circ} \mathrm{C}\right)$ & $\alpha_{y}\left(\mu /{ }^{\circ} \mathrm{C}\right)$ \\
\hline Glass/epoxy lamina & 23.8 & 9.1 & 3.4 & 0.31 & 7.9 & 38.6 \\
Aluminium sheet & 69 & 69 & 25 & 0.33 & 23.6 & 23.6 \\
\hline
\end{tabular}


Table 3: Average measured strains $(\mu \mathrm{m})$ for FML specimens with $\left[\mathrm{AL} / \mathrm{O}_{2}^{\circ} / 90_{2}^{\circ}\right]_{\mathrm{S}}$ laminate

\begin{tabular}{cccc}
\hline \multirow{2}{*}{ depth $(\mathrm{mm})$} & \multicolumn{3}{c}{ Gauge direction } \\
\cline { 2 - 4 } & $\varepsilon_{1}\left(\theta=0^{\circ}\right)$ & $\varepsilon_{2}\left(\theta=45^{\circ}\right)$ & $\varepsilon_{3}\left(\theta=90^{\circ}\right)$ \\
\hline 0.4 & -27.91 & -24.84 & -26.77 \\
0.8 & 51.13 & -15.16 & -77.51 \\
1.2 & -4.09 & -4.59 & 4.42 \\
\hline
\end{tabular}

Table 4: Comparison between experimental data and theoretical calculations of residual stresses for $\left[\mathrm{AL} / \mathrm{O}_{2}^{\circ} / 90_{2}^{\circ}\right]_{S}$ laminate

\begin{tabular}{|c|c|c|c|c|c|c|c|c|c|c|c|c|}
\hline \multirow{2}{*}{$\begin{array}{l}\text { Stress } \\
(\mathrm{MPa})\end{array}$} & \multicolumn{4}{|c|}{ First step $\left(h_{i}=0.4 \mathrm{~mm}\right)$} & \multicolumn{4}{|c|}{ Second step $\left(h_{i}=0.8 \mathrm{~mm}\right)$} & \multicolumn{4}{|c|}{ Third step $\left(h_{i}=1.2 \mathrm{~mm}\right)$} \\
\hline & A & $\mathrm{B}$ & $\mathrm{C}$ & $\mathrm{D}$ & $\mathrm{A}$ & B & $\mathrm{C}$ & $\mathrm{D}$ & $\mathrm{A}$ & B & $\mathrm{C}$ & $\mathrm{D}$ \\
\hline$\sigma_{x}$ & 9.18 & 9.15 & 0.03 & 0.3 & -13.26 & -14.81 & 1.52 & 10.3 & 4.20 & 5.66 & 1.46 & 25.8 \\
\hline$\sigma_{x y}$ & -0.26 & 0 & -0.26 & - & 0.60 & 0 & 0.60 & - & 0.31 & 0 & 0.31 & \\
\hline$\sigma_{y}$ & 8.87 & 9.15 & 0.28 & 3.1 & 4.77 & 5.66 & 0.89 & 15.7 & -12.76 & -14.81 & 1.05 & 13.8 \\
\hline
\end{tabular}

A: Experimental results; B: Theoretical predictions; C: Difference; D: Percent of errors; 